\title{
Validation of the Calgary Symptoms of Stress Inventory (C-SOSI) for Predicting Adherence to a Stress Reduction Technique
}

Lauren M. Penwell

West Virginia University

Follow this and additional works at: https://researchrepository.wvu.edu/etd

\section{Recommended Citation}

Penwell, Lauren M., "Validation of the Calgary Symptoms of Stress Inventory (C-SOSI) for Predicting Adherence to a Stress Reduction Technique" (2012). Graduate Theses, Dissertations, and Problem Reports. 4909.

https://researchrepository.wvu.edu/etd/4909

This Dissertation is protected by copyright and/or related rights. It has been brought to you by the The Research Repository @ WVU with permission from the rights-holder(s). You are free to use this Dissertation in any way that is permitted by the copyright and related rights legislation that applies to your use. For other uses you must obtain permission from the rights-holder(s) directly, unless additional rights are indicated by a Creative Commons license in the record and/ or on the work itself. This Dissertation has been accepted for inclusion in WVU Graduate Theses, Dissertations, and Problem Reports collection by an authorized administrator of The Research Repository @ WVU.

For more information, please contact researchrepository@mail.wvu.edu. 


\title{
Validation of the Calgary Symptoms of Stress Inventory (C-SOSI) for Predicting Adherence to a Stress Reduction Technique
}

\author{
Lauren M. Penwell, M.A.
}

\begin{abstract}
Dissertation submitted to the Eberly College of Arts and Sciences
at West Virginia University

in partial fulfillment of the requirements for the degree of

Doctor of Philosophy in Psychology
\end{abstract}

Kevin Larkin, Ph.D., Chair

Amy Fiske, Ph.D.

Julie Hicks-Patrick, Ph.D.

William Reger-Nash, Ed.D.

Jeannie Sperry, Ph.D.

Department of Psychology

Morgantown, WV

2011

Keywords: stress; stress management; coping; adherence; cardiovascular reactivity 


\begin{abstract}
Validation of the Calgary Symptoms of Stress Inventory (C-SOSI) for Predicting Adherence to a Stress Reduction Technique
\end{abstract}

\title{
Lauren M. Penwell
}

Stress is a ubiquitous aspect of modern life that has serious effects on mental and physical health. Many stress reduction techniques are currently available to help combat these effects but non-adherence to them is a significant barrier to their overall effectiveness. The aims of the current study were to: 1) validate the Calgary Symptoms of Stress Inventory (C-SOSI), an instrument that classifies one ${ }^{\text {ee }} \mathrm{s}$ stress response profile, using traditional psychometric procedures as well as for predicting responses to a laboratory stress situation, and 2) explore the utility of this instrument for predicting adherence following training in a single stress reduction session using guided breathing. Seventy undergraduates ( 55 women, $15 \mathrm{men}$ ) participated in a laboratory study in which they reported their typical stress responses using the C-SOSI, and their actual cognitive, affective, and cardiovascular responses to two stressful tasks were assessed. Next, all participants were trained in and practiced a diaphragmatic breathing relaxation strategy. Adherence, efficacy, and enjoyment of daily practice of the relaxation strategy were measured during a two-week follow-up phase using a web-based recording system. Although internal consistency reliabilities were generally acceptable for the C-SOSI subscales (Cronbach alphas ranging from .78 to .94), the validity of the C-SOSI subscales for explaining variance in actual stress responses to laboratory stressors was not as expected. The C-SOSI Affect subscale explained a significant amount of variance in the cognitive response to stress in the laboratory $\left(R^{2}=.21, p<.01\right)$, and the C-SOSI Physiology subscale explained a significant amount of variance in both the affective and physiological responses to stress in the laboratory $\left(R^{2}=.28, p\right.$ $<.01$, and $R^{2}=.22, p<.01$, respectively). None of the C-SOSI subscales explained adherence to daily practice, efficacy, or enjoyment of the breathing relaxation strategy. Participants with both greater active coping and aggregated physiological responses to laboratory stress rated their practice of the relaxation strategy as being more enjoyable than participants with lower responses in both of these domains. In summary, although the C-SOSI Physiology subscale was shown to be associated with actual physiological and affective responses to laboratory stressors, the other subscales of the C-SOSI fared less well, and no C-SOSI subscale was associated with any measure of adherence to daily practice, efficacy, or enjoyment of the breathing relaxation strategy used in this study. Because this study was the first to attempt to demonstrate the validity of the C-SOSI, the instrument requires further attention in future empirical work on measuring the stress responses of healthy adults as well as individuals suffering with a range of medical diseases. 


\section{Acknowledgements}

I would like to recognize the following individuals for their assistance in completing this project: Heather Elsey, for her help in collecting and entering data; Brian Creasy, for his audio expertise in helping me to make guided breathing recordings; my committee members for their invaluable knowledge and guidance in developing the study; my fellow behavioral physiology labmates for their consultation and support; and the psychology department alumni who so generously contribute to the funding that helped to make this research possible. I would especially like to thank my mentor, Kevin Larkin, for his constant support and guidance over the years. I also would like to acknowledge the Physics Department at the University of Kuopio, Finland, for making their HRV analysis software freely available. 


\section{IRB Acknowledgement}

I verify that I obtained IRB approval prior to initiating data collection for this project. I also verify that my research was conducted in strict adherence to the approved protocol. No amendments to the protocol were required during data collection and appropriate continuing reviews were completed according to the standards established by the IRB. 
Table of Contents

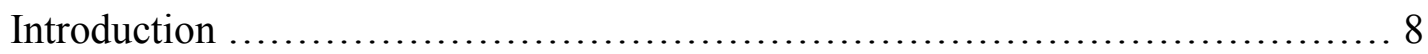

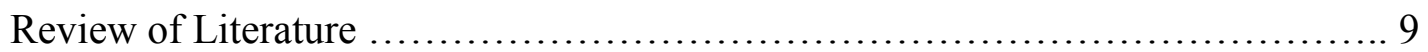

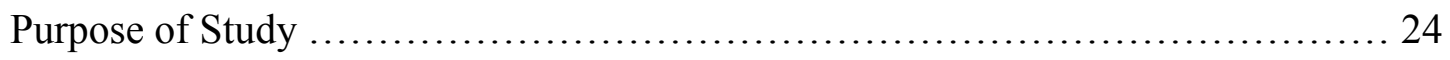

Method ............................................................ 29

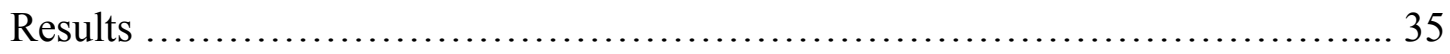

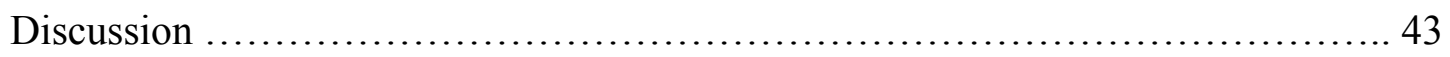

References ............................................................. 58

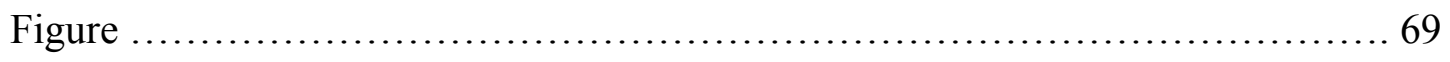

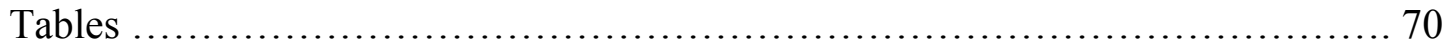

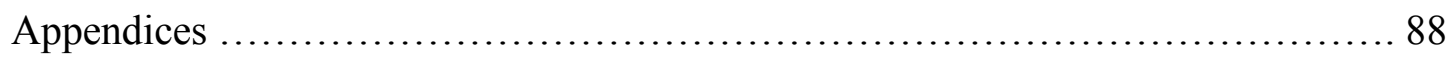

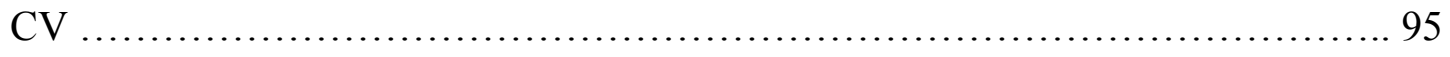




\section{List of Figures}

Figure 1. Flow of participants in study. 


\section{List of Tables}

Table 1. Demographic variables of participants and those who were invited to participate but declined.

Table 2. Descriptive statistics of C-SOSI subscales for the study sample.

Table 3. Means (standard deviations) for items on the daily questionnaire.

Table 4. Means (standard deviations) of all study variables for men and women.

Table 5. Correlations among study variables.

Table 6. Means (standard deviations) for cognitive, affective, and cardiovascular response to the hand grip and mental arithmetic tasks.

Table 7. Regression statistics for predicting coping and cognitive anxiety responses from C-SOSI subscales.

Table 8. Regression statistics for predicting affective responding from C-SOSI subscales.

Table 9. Regression statistics for predicting cardiovascular reactivity from C-SOSI subscales.

Table 10. Regression statistics for predicting daily relaxation practice from C-SOSI subscales.

Table 11. Regression statistics for predicting daily relaxation practice from lab responses. 
Validation of the Calgary Symptoms of Stress Inventory (C-SOSI) for Predicting Adherence to a Stress Reduction Technique

Stress has been viewed alternatively as a physiological reaction, a collection of environmental aggravations, a cognitive appraisal of threat, a stimulus-response interaction, or an imbalance between environmental demands and personal resources, among other things (e.g., Beck, 1993; Gadzella, 1994; Larkin, 2005; Matheny, Aycock, Curler, \& Junkette, 2003). On one hand, when people refer to „work stress, ", „financial stress, ${ }^{\text {,e }}$ or ,interpersonal stress, ${ }^{\text {,e the }}$ connotation appears to reflect external environmental stimuli that occur in daily life. On the other hand, when people refer to the discomfort that stress plays in their lives or when they feel „stressed out, "stress appears to reflect internal responses to life situations. To complicate matters, stress also can be categorized by time frames of occurrence: acute, sequential, chronic but intermittent, and chronic (Cohen, 2000). For the purposes of the proposed project, stress will be conceptualized as a stimulus-response interaction that involves both environmental challenges people confront in their daily lives (i.e., stimuli) and the individualized patterns of response that follow. The term „stressor" will be used when referring to environmental stimuli that threaten or challenge organisms engaged in daily living, and the term „stress response ${ }^{e e}$ will be used when referring to the various types of reactions organisms exhibit in response to these environmental stimuli. The current paper focuses on the stress response, so it will be introduced first, with an emphasis on the physiological sequelae of exposure to environmental stressors. Next, methods of measuring the stress response will be described. Finally, as stress is a common reason for seeking help in healthcare settings, the application of the measurement of the stress response and its proposed importance in predicting outcomes to stress reduction programs will be considered. 


\section{The stress response}

It is generally agreed that the stress response involves four broad domains of functioning: cognitive, behavioral, physiological, and emotional (e.g., Avero \& Calvo, 1999; Cohen, 2000; Cohen \& Rodriguez, 1995; Larkin, 2005). Affective responses to stressors may include such feelings as anxiety, depression, or anger, among other things. Behaviorally, individuals may exhibit any number of responses, among them forms of escape, increased substance use, or social withdrawal. Cognitive processes may be consumed by worry, rumination, or catastrophic thinking about the stressor. Physiological processes, which will be discussed more in depth, generally involve arousal of the autonomic nervous system, leading to a wide array of physiological changes in the body (Larkin, 2005). These different domains of the stress response are often difficult to tease apart, and there is some debate about the order in which they occur and whether individual differences exist in the sequence and patterning of these various domains of the stress response. For example, in their early work on this topic, Schwartz, Davidson, and Goleman (1978) highlighted three of these domains of the stress and anxiety response: cognitive, behavioral, and somatic (i.e., physiological). They hypothesized that stress management techniques might be more or less effective depending on which of these response domains were prominent within a particular person ses stress response profile. In line with this theory, Cohen and Rodriguez (1995) proposed that emotionally upsetting events affected individuals via physiological, cognitive, behavioral, and social pathways. Accordingly, the emotional component took center stage, but immediate physiological reactions to stress were undeniable, as were cognitions. Similarly, in an examination of the James-Lange theory of emotion, physiological perception and emotional perception were found to be correlated (Pollatos, Kirsch, \& Schandry, 2005), providing additional evidence that stress responses among these domains 
were not orthogonal. Even when considering only affect, it is impossible to extricate a singular component using Folkman and Lazaruse (1991) definition of emotions as "psychophysiological reactions consisting of cognitive appraisals, action impulses and patterned somatic reactions" (p. 209). Beck (1993) suggested that individuals engage in the cognitive appraisal process first, before acting and experiencing emotions in response to a stressful situation. Folkman and colleagues (1986) build upon this assertion, noting that individuals base their coping responses upon their appraisals of threat. Integrating these multiple theories of stress and coping, there is convincing evidence that the varying domains of the stress response overlap and influence one another.

It must be acknowledged that stress is a part of everyday life, and while uncomfortable, has important evolutionary significance. Stress responses can be beneficial, and the body systems $^{\text {ee }}$ reactions can be life-saving. Among human ancestors, failure to exhibit healthy stress responses to life-threatening stimuli more frequently resulted in death and/or serious injury than exhibiting less substantial stress responses. For example, human ancestors who reacted with strong fight-flight responses to animals that threatened their lives were more likely to survive than those who failed to respond to these sources of threat in their environments. Even in more contemporary times, it could be argued that exposure to some degree of stress facilitates job performance, motivation to achieve, and educational and occupational success.

Despite the life-sustaining and productive consequences of stress responses, there are many negative psychological and physical consequences of stress responses, mainly when they occur too frequently, too intensely, and last for substantial periods of time. One statistic suggests that a large number of annual deaths are partly attributable to stresses associated with the modern lifestyle (Cohen, 2000). Poor stress management has been linked with myriad complications for 
both mental and physical health, among them cardiovascular disease, memory problems, inflammatory diseases, difficulties with problem solving, and emotional turmoil (e.g., Cohen \& Rodriguez, 1995; Ellins et al., 2008; Lovallo, 1997; Patel, 1993; Steinhauser, Maier, \& Hübner, 2007).

It is generally believed that stress exerts its negative effects on health through a cascade of physiological events including activation of the autonomic nervous system, secretion of stress hormones like cortisol and the catecholamines from the neuroendocrine system, and disruptions of the immunological system responsible for protecting the body from infections and other foreign substances. Cannon (1928) first described these effects as an organism ${ }^{\text {ee }}$ attempts to maintain homeostasis in the face of stressors. In contrast to the regulatory process of homeostasis, which involves the body ${ }^{\text {ee }}$ maintenance of equilibrium in a relatively static environment, McEwen (1998) labeled the process ,,allostasis, ${ }^{\text {ee }}$ which refers to the body to maintain stability of functioning in an unstable or changing environment. The constant struggle to maintain emotional and physiological stability as the organism confronts and responds to environmental threats and challenges produces a physiological strain in the body known as allostatic load.

The bodyes endeavor to maintain allostasis most commonly involves activation of the hypothalamic-pituitary-adrenocortical (HPA) axis and the sympathetic adrenomedullary system (McEwen, 1998). These systems are involved in the response to acute stressors (in the fight-orflight response) and often result in increased heart rate, respiration rate, and blood pressure; the body uses a similar response to defend against chronic stressors (Ader, Cohen, \& Felten, 1995; Lovallo, 1997). Of course, the process must also involve inactivation when the stressor is no longer present. The inability of the body to inactivate the HPA axis response efficiently upon 
termination of exposure to a stressor or frequent activation of the HPA axis response exposes the body to an overabundance of these stress hormones, leading to allostatic overload and the healththreatening physiological outcomes that occur with it (McEwen, 1998).

According to McEwen (1998), there are four ways in which allostatic load becomes problematic. First, frequent exposure to stressors causing repeated activation of the system can weaken the body and cause health problems. Second, if the body does not adapt to these repeated exposures to stress (i.e., failure to habituate), the same elevated physiological responses will be exhibited, leaving the body exposed to stress hormones for prolonged periods of time. Third, an inability of the system to be inactivated following exposure to stress (i.e., prolonged recovery) allows the stress hormones to circulate for a longer period of time than is necessary. In a final scenario, the body may fail to respond to stressors with one physiological system so another is activated to compensate. McEwen (1998) notes that when the HPA axis does not respond appropriately (in this case, a deficient level of activation), the immune system increases production of cytokines which can have an equally deleterious effect. Although the immune system is generally proficient at handling the bodyes demands, disruptions in normal functioning occur when individuals are exposed to prolonged stressors. For instance, the glucocorticoids (of which cortisol is the most prominent), have been shown to suppress the immune system and result in an increased production of proinflammatory cytokines (Ader et al., 1995). After initially conferring an enhanced immunologic state, the prolonged presence of these immune bodies maintains an inflammatory condition, leaving the body susceptible to infection and increased risk for autoimmune disease (Ader et al., 1995; McEwen, 1998). There is evidence that through practicing common stress management strategies, the physiological processes that define allostatic load can be modulated. For example, asthma patients practicing biofeedback-assisted 
relaxation experienced decreased inflammation and better pulmonary function compared to controls (Kern-Buell, McGrady, Conran, \& Nelson, 2000). Additionally, participants practicing progressive muscle relaxation produced less salivary cortisol than did controls in another study (Pawlow \& Jones, 2005). These results indicate that it is possible to mitigate the physiological consequences of stress; this will be discussed in more detail in a later section of this dissertation.

Heart rate variability (HRV) has become an increasingly popular measure of physiological responding to stress. In its most basic terms, HRV is a change in the beat-to-beat activity of the heart over time. These changes are influenced by both sympathetic and parasympathetic innervation, making this process particularly interesting to researchers studying stress (Berntson et al., 1997). In general, greater HRV is associated with an enhanced ability to adapt to stress physiologically, and reduced HRV indicates an inability to adapt, which is often associated with a vulnerability to stress-related illnesses (Wheat \& Larkin, 2010), similar to the model of allostatic load previously described. Recent research has indicated that HRV is tied to several biomarkers of systemic inflammation through anticholinergic activity of the vagus nerve, further implicating its importance in disease processes, particularly cardiovascular and kidney disease (Haensel, Mills, Nelesen, Ziegler, \& Dimsdale, 2008). This association may be especially pronounced in depressed patients with heart disease (Frasure-Smith, Lesperance, Irwin, Talajic, \& Pollock, 2009), but it is also evident in healthy adults (Thayer \& Fischer, 2009; von Kanel, Nelesen, Mills, Ziegler, \& Dimsdale, 2008).

To summarize, the stress response is a necessary reaction to help individuals cope with environmental demands. However, an exaggerated response, too frequent activation of the response, or a prolonged response sets in motion a chain of physiological events that, over time, 
can disrupt the body ${ }^{\text {ee }}$ delicate balance and cause injury to the cardiovascular and immune systems, resulting in negative health outcomes for individuals.

\section{Measurement of stress}

As previously described, there are a variety of ways to conceptualize stress. One conceptualization of stress will clearly influence the way in which measures of stress are devised and selected; thus, there are different scales to measure stress as a stimulus, as a response, or as an interaction between the two. For example, Selye (1956) depicted stress as a response in his description of the General Adaptation Syndrome. An important part of his model was the focus on the physiological response to stressors and the ensuing health outcomes that resulted from prolonged exposure to numerous types of stressors. It is not surprising then that Selye measured stress using direct measures of physiological disturbance, including presence of gastric ulcers in stressed animals. In contrast, Holmes and Rahe (1967) conceptualized stress as a series of environmental aggravations, and their measure (the Social Readjustment Rating Scale) is essentially a list of common environmental life stressors people encounter (e.g., death of a loved one, losing a job, purchasing a home, having a baby). The Daily Stress Inventory (DSI; Brantley, Cocke, Jones, \& Goreczny, 1988), the Daily Inventory of Stressful Events (DISE; Almeida, Wethington, \& Kessler, 2002), and the Student Life-Stress Inventory (Gadzella, 1994) assess both the stressors present in one $\mathrm{s}$ environment and how intensely an individual reacts to them, following a transactional stimulus-response model. The DSI and the DISE assess the perceived intensity (as well as prevalence) of multiple daily stressors. Although these methods attempt to measure an individual's reactions to stressors, they do not assess the patterning or sequence of specific responses, only the respondent ${ }^{e e}$ s overall perceptions of stressfulness. 
Clinically, it is generally thought to be more useful to know about a person"s stress response rather than the types of particular environmental stressors he or she confronts. Although it is important to recognize the environmental precipitants of an exaggerated stress response, the therapist and client have more control over the latter part of the equation. Unfortunately, the aforementioned measures of stress, either lists of environmental stimuli or general perceptions of stressfulness, have not been all that useful in clinical settings. To develop a more useful assessment tool that provides a comprehensive measure of one $\mathrm{e}^{\mathrm{ee}}$ stress response profile, including domains of affective, cognitive, behavioral, and physiological responding, the Calgary Symptoms of Stress Inventory (C-SOSI) was developed. The purpose of this instrument was to examine the somatic, cognitive, and behavioral symptoms of stress that were altered following a mindfulness stress reduction treatment program (Carlson \& Thomas, 2007). Although items were selected to measure these three specific response domains, a factor analysis of scale items did not yield a three factor solution. Factors on the C-SOSI that emerged included: Depression, Anger, Cognitive Disorganization, Muscle Tension, Cardiopulmonary Arousal, Sympathetic Arousal, Neurological/Gastrointestinal Symptoms, and Upper Respiratory Symptoms. As this scale was developed and used within the context of a psychooncology unit, it placed a significant emphasis on somatic manifestations of stress; it is thus unclear if the factors identified would be similar in a population of individuals without a major medical concern. However, the sub-scales that were identified appeared to be strong, as internal consistency alphas were .80 or above for all factorderived subscales and for the total score.

Koh, Park, Kim, and Cho (2001) also attempted to develop an inventory grounded in the four factor theory of stress responding (i.e., emotional, cognitive, behavioral, and physiological). They found that, although these four general domains were evident among the items devised, the 
specific factors observed did not support a four-factor solution. A factor analysis revealed that their Stress Response Inventory was composed of seven factors which were named Tension, Aggression, Somatization, Anger, Depression, Fatigue, and Frustration. This scale is unique in that it was developed using a Korean population, using the experiences of Korean psychiatrists and psychologists to develop some of the items. It has not yet been validated for use in Western, English-speaking nations. The instrument shows promise, however, as various estimates of reliability indicated that the SRI consistently measured robust factor constructs.

Gadzella (1994) was more successful in uncovering a four factor solution on the stress response portion of the Student-Life Stress Inventory. However, a weakness of the scale is that the cognitive component was measured by only two items and the emotional component only by four items. The behavioral and physiological subscales were comprised of more items, suggesting that the factors observed may not represent the full range of potential stress responses. Additionally, Cronbach's alphas varied for the measurement of stressful situations, with some trending toward the unacceptable range (e.g., .52 for Frustration), bringing into question the reliability of this measure of stress. The factor analytic methods used in the development of the scale were not reported, also leading to some questions about the factor structure of the instrument.

Although several studies (Carlson \& Thomas, 2007; Gadzella, 1994; Koh et al., 2001) have attempted to measure the stress response profile comprehensively with the aim of developing a more clinically useful tool for appraising the pattern and sequence of the stress response, they all have some weaknesses and require further validation. For example, none of these instruments have been validated to determine whether participant responses on them are associated with the actual cognitive, behavioral, affective, or physiological responses observed 
during exposure to a stressful situation, nor have they been tested for usefulness in selecting a treatment modality.

\section{Stress management}

As previously noted, knowledge about the stress response could have important clinical applications for stress reduction. None of the reviewed instruments has been used in a study attempting to predict an individual 's response to a particular stress management intervention. In this regard, if a measure of stress response is not associated with treatment outcomes, such an instrument, though informative, may not be useful clinically.

Given the numerous negative psychological and physical consequences of stress, it is imperative that individuals learn to cope or manage the stress in their lives. Lazarus and Folkman (1984) defined coping as "constantly changing cognitive and behavioral efforts to manage specific external and internal demands that are appraised as taxing or exceeding the resources of the person" (p. 141), which mirrors the conceptualization of stress and the stress response previously described. Coping can be conceptualized in various ways, though among the most common distinctions are approach vs. avoidant coping and emotion-focused vs. problem-focused coping. Approach coping involves actively addressing stressful stimuli, whereas avoidant coping relies on strategies to distract oneself from the stressor. Similarly, problem-focused and emotionfocused coping represent attempts to manipulate some part of the stressful transaction (the stimulus in the former and the emotional response in the latter). Lazarus and Folkman (1984) note that no strategy is inherently good or bad; rather, the usefulness of the strategy employed is judged by the outcomes it induces. This dynamic process has been referred to as goodness-of-fit, as effective coping strategies are selected based upon the demands of the stressful situation, specifically how controllable it is. The goodness-of-fit hypothesis has received some empirical 
support, indicating that individuals generally do match their coping strategy of choice (problemfocused or emotion-focused) with the controllability of the stressor, and this attempt often results in less distress. Accordingly, problem-focused coping appears to be more beneficial in response to stressors for which respondents exert some control (e.g., one can reduce risk of heart disease by stopping smoking) and that emotion-focused coping appears to be more beneficial in situations in which respondents confront uncontrollable outcomes (e.g., praying for comfort while dying from an incurable disease). Findings supporting the goodness-of-fit hypothesis, however, have been equivocal, with some studies indicating greater distress when there is a mismatch between appraisals and coping responses; however, other studies have not supported this association and instead found main effects for overall coping effectiveness, regardless of specific type (Forsythe \& Compas, 1987; Park, Folkman, \& Bostrom, 2001; Zakowski, Hall, Klein, \& Baum, 2001).

Stress management in its myriad forms could be viewed as a type of emotion-focused coping, as its aim is to regulate the emotional response to stress, thereby decreasing the physiological effects of stress. The use of complementary medicine, which includes stress management and relaxation techniques, has risen in recent years, and deep breathing exercises are among the most widely used strategies (Barnes, Bloom, \& Nahin, 2008). In early studies of relaxation techniques, Benson (1975) proposed that their apparent effectiveness stems from their ability to reduce autonomic arousal and offset the damages produced by repeated physiological arousal. Among the beneficial physical changes of various stress management techniques, he lists decreased oxygen consumption, respiratory rate, heart rate, blood pressure, and muscle tension, and increased production of alpha waves, which are all part of the relaxation response. 
Repeated elicitation of the relaxation response is thought to decrease blood pressure and alleviate other stress-related illnesses.

Although there are several unique stress management techniques that are commonly practiced, Benson (1975) states they all have in common certain characteristics that are integral to the practice and to bringing about the relaxation response. The four basic components are a quiet environment in which to practice, mental focus, a passive attitude, and a sitting position that minimizes muscle tension. However, the practice of stress management itself may not be so basic, as each of the strategies requires a significant commitment on the part of the learner to engage in regular practice to acquire, strengthen, and maintain his or her skill with the chosen technique. Given the length of time required to learn and master these skills, it is important to select a strategy that will be both acceptable to the client and result in positive health outcomes. Engaging in regular practice of a stress management technique that does not ameliorate the negative aspects of one $e^{\text {ee }}$ stress response profile is problematic, as is selecting a technique that works for the client, but is one he or she is not interested in practicing. In this regard, it is important to optimize the match between a specific stress management strategy chosen and the

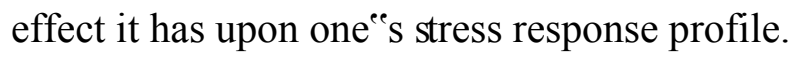

Although most stress management techniques have been shown to result in changes in the autonomic, somatic, and central nervous systems, specific strategies have been hypothesized to influence these physiological processes differentially. For example, meditation is generally thought to influence the stress response via central nervous system de-activation, while progressive muscle relaxation is thought to influence the stress response via reductions in somatic nervous system activity (Lehrer, Schoickett, Carrington, \& Woolfolk, 1980). Using this conceptualization, it could be suggested that stress management techniques are differentially 
efficacious for individuals exhibiting differing types of stress reactivity profiles. With the practice of yoga, for example, there are different paths one develops with continuing practice: a physical path, a cognitive path, a behavioral path, and a devotional path. Though they are not isolated, the labeling of these different paths points to an acceptance of the four domains in which stress reduction may be most pertinent (Patel, 1993).

As the domains of stress reactions overlap, so do the effects of various stress reduction strategies. It is not likely that someone practicing a particular stress management technique would see improvements in only their cognitive processes and another person practicing a different technique would experience an alleviation of only affective symptoms. Nevertheless, a „,specificity ${ }^{e e}$ hypothesis has been proposed that states that when efforts are made to match one ${ }^{e e}$ stress response profile with a specific stress management intervention, outcomes will be optimized (Schwartz et al., 1978). This specificity hypothesis closely resembles the goodness-offit hypothesis proposed in the coping literature (Lazarus \& Folkman, 1984). Accordingly, people who respond to stress with exaggerated somatic nervous system responses (e.g., muscle tension) will exhibit the greatest reduction in stress when practicing a strategy aimed at reducing somatic tension (e.g., progressive muscle relaxation). Congruently, people who respond to stress with exaggerated cognitive responses (e.g., catastrophic attributions) will exhibit the greatest reduction in stress when practicing a strategy aimed at reducing cognitive stress responses (e.g., cognitive restructuring). There was some early support for this theory, with one study showing that individuals engaging in aerobic exercise for stress reduction experienced less somatic and more cognitive anxiety following training than individuals using meditation (Schwartz et al., 1978). In contrast, individuals engaging in meditation experienced less cognitive anxiety and more somatic anxiety following training than the exercise trainees. In another study comparing 
PMR and meditation, individuals engaging in either technique experienced a greater reduction in state anxiety than did individuals in a control group after exposure to a brief stressor, but those engaging in PMR saw greater decreases in somatic anxiety than did the other two groups; no such interactions were observed for cognitive anxiety (Rausch, Gramling, \& Auerbach, 2006). Meditation also has been reported to have less of an effect on hypertension than PMR (Lehrer \& Woolfolk, 1993). These studies appear to suggest that different stress reduction techniques (in this case PMR and meditation) effect different outcomes on one $e^{\text {ee }}$ stress response profile. However, this "specific effects" model has not been well-supported by all studies. In fact, results from multiple studies comparing the relative effectiveness of various stress reduction techniques have been mixed (Lehrer \& Woolfolk, 1993; Rausch, Gramling \& Auerbach, 2006). It is now believed that some additional specific effects may be seen within the context of a more general “relaxation response” (Lehrer \& Woolfolk, 1993). In support of this modified specificity hypothesis, Carrington (1993) listed positive gains from a regular meditation practice across all four domains, counting among the benefits increased mood and productivity, reduced anxiety and irritability, fewer illnesses, a heightened sense of self-awareness, and improved decision making skills. Although beneficial influences are evident across domains, those that occur in the area in which an individual feels the effects of stress most acutely (i.e. the domain in which he or she most intensely reacts to a stressor) may be detected most easily by the learner.

\section{Adherence to stress management}

Various stress reduction techniques have been used successfully in the treatment of hypertension, migraine headache, insomnia, anxiety disorders, and other ailments (Lehrer \& Woolfolk, 1993; Patel, 1993). Of course, in order for one to experience the benefits of a stress management program, one must actively engage in it and practice it on a daily basis. Adherence 
is not guaranteed; in fact, many health professionals struggle with motivating their clients to adhere to any treatment recommendations, including those related to stress management (Lehrer \& Woolfolk, 1993). In a review of published studies regarding adherence to stress management programs, Lehrer and Woolfolk (1993) found that roughly 50 percent of individuals who had begun meditating stopped after three or six months of practice. Given the difficulties with continuity of treatment, much empirical focus has been set on adherence to clinical recommendations, with a variety of theories being explored.

Early research suggested many possible reasons why patients may not regularly practice stress reduction techniques, including unrealistic expectations for the results of practice, beliefs that practice will not influence risk for disease (e.g., external health locus of control), unpleasant or unfamiliar physiological sensations that accompany the practice, and other intervening variables, such as presence of depression or other psychiatric disorders (Lehrer \& Woolfolk, 1993). More recently, engagement in specific health behaviors has been examined as a factor that influences adherence to regular practice. For example, active coping has been associated with better adherence to medication regimens among patients with HIV, whereas avoidant coping was related to missing doses (Vyavaharkar et al., 2007; Weaver et al., 2005). Cognitive and affective reactions to a behavior also may be important in the adoption of a behavior; individuals who rated a variety of health promoting behaviors to be more enjoyable and more beneficial reported higher intentions to engage in those behaviors (Lawton, Conner, \& McEachan, 2009).

More recently, psychology has integrated concepts from behavioral economics to study health behaviors, including adherence to treatment recommendations. Delay discounting of reinforcement is one such area of focus that may provide a context for understanding preventive health behaviors. Delay discounting of reinforcement is a phenomenon that involves choosing an 
immediate but small reward instead of a more substantial reward later. For example, an individual with a lesser propensity for delay discounting may choose to forgo a fattening dessert at a meal in favor of the long-term health benefits of maintaining a healthy diet. In contrast, an individual who prefers more immediate rewards (engages in more discounting of delayed rewards) may be less likely to engage in current health behaviors, including adhering to medication regimens and other treatment recommendations. Consistent with this theory, patients may engage in a cost-benefits analysis of engaging in a particular stress management program, in which the cost (e.g., time committed to daily practice) is contrasted with the perceived long term health benefits of daily practice. Often, the harmful health effects of stress are not immediately recognizable and the beneficial health effects of stress management are not easily detected, whereas the direct and indirect costs associated with acquisition and maintenance of the stress management practice are relatively noticeable; this renders the decision to follow professional advice regarding stress management tenuous at best (Lamiruad \& Geoffard, 2007; Patel, 1993). Even if the practice of stress management prolongs life and results in reduced risk for chronic diseases, these results will not be realized if persons do not adhere to their regular practice. Finding ways to keep patients engaged in stress management programs has become increasingly important among clinicians as they deal with more and more patients suffering from the effects of chronic stress. The area of health behavior economics must be advanced to further illuminate the reasoning behind patients ${ }^{e e}$ health decisions, as results of studies in this line of inquiry are mixed, indicating that the theory may not yet be fully developed (Chapman et al., 2001).

Another factor that may be important in predicting adherence pertains to the type of stress management method selected and how well it matches with the client ${ }^{\text {ee }}$ s stress response profile. There is a large body of research examining attempts to match psychological treatments to client 
characteristics to achieve the best results, based on the theory that treatments that address a particular need or deficit of a client will deliver the most noticeable outcomes (Mattson \& Allen, 1991). Much of this research has been conducted with regard to treatment for substance abuse (e.g., Project MATCH), but it may also be fruitful to examine with other types of treatments. Selecting stress management strategies based upon personality types of clients has been unsuccessful thus far, but other factors may be pertinent. For example, absorption, or the ability to be completely focused on something, has been indicated as a beneficial trait for predicting adherence to the practice of meditation (Carrington, 1993). Additionally, if a certain component to a stress reduction technique appealed to a client, it could be more likely to promote adherence to daily practice and the positive outcomes that follow (Lawton et al., 2009). Synthesizing this information with the specificity hypothesis previously described, it could be predicted that a stress management technique that addressed a particular stress response (i.e. brought additional relief within that response domain) would be perceived as more beneficial and more enjoyable by the individual; thus, the individual may be more likely to engage in that behavior. Mattson and Allen (1991) note, "the ultimate goal of matching research is to develop valid and practical rules for assigning patients to treatment regimens particularly suited to them" (p. 34). These rules must still be developed for assignment to stress management therapies. Thus, a specific aim of the present investigation is to examine potential rules for promoting adherence to a specific stress reduction strategy through assessing individual's stress response profiles.

\section{Purpose of the Study}

The stress response, though necessary at times, can be harmful to the body and disrupt normal functioning if it is experienced too intensely, too frequently, for too long, or if it triggers an unhealthy response in the body by other response systems. Strategies to manage the stress 
response are important for improving the mental and physical health of the public. There is evidence that many people are willing to try various stress management techniques, but adherence to daily practice is considerably less than perfect. For individuals to experience the full benefits of a stress management technique, regular practice is a necessity.

In a related area, studies have attempted to quantify the specific effects of stress reduction techniques in order to examine and understand how the stress response is affected by these interventions. Most recent studies have focused on responding within four domains: affective, behavioral, cognitive, and physiological. Before this line of work can progress, however, researchers and clinicians must be able to better assess how an individual typically responds to stressors. As the stress response is more likely to be controllable than the presence of stressful environmental stimuli, understanding the elements of the stress response is crucial to predicting treatment outcome and the magnitude of reduction in stress. To this end, the primary purpose of this study was to validate a promising stress response inventory, the C-SOSI, both by examining its associations to actual responses observed during exposure to stress and to determine its efficacy in predicting response and adherence to a common stress management strategy. The CSOSI was chosen over other available stress inventories (e.g., Gadzella, 1994; Koh et al., 2001) due to its demonstrated internal consistency reliabilities and factor structure that differentiates among cognitive (Cognitive Disorganization), affective (Depression, Anger), and physiological domains (Muscle Tension, Cardiopulmonary Arousal, Sympathetic Arousal, Neurological/Gastrointestinal Symptoms, and Upper Respiratory Symptoms).

The present study sought to find convergent validity for the various C-SOSI subscales by comparing participants ${ }^{e e}$ responses to the inventory to their responses when they are actually exposed to laboratory stressors. Thus, the Anger and Depression subscales were examined as 
indicators of affective stress responding, the Cognitive Disorganization subscale as an indicator of cognitive stress responding, and the remaining subscales as indicators of physiological stress responding. As it has been demonstrated that cardiovascular reactivity in the lab is a fair predictor of ambulatory measures of heart rate and blood pressure responses to actual environmental stressors, one could reasonably assume that responses to stressor tasks observed in the laboratory would reflect reactions to stressful situations that occur in daily life (Fahrenberg, Foerster, \& Wilmers, 1993). Thus, it was hypothesized that participants would exhibit a similar pattern of stress responding in the laboratory as they reported on the C-SOSI inventory regarding stress response to real life situations. The three domains being studied (cognitive, affective, and physiological) were chosen because problems are likely to be manifested in each in response to stressors in vivo. As previously noted, stress has been associated with cognitive disturbances (e.g., difficulty concentrating; Steinhauser et al., 2007), affective disturbances (e.g., anxiety and depression; Cohen \& Rodriguez, 1995), and physiological reactions (e.g., sympathetic arousal, immune system dysregulation; Ader et al., 1995). These corollaries of stressors are likely to cause interruptions in normal functioning at work or school, in interpersonal relationships, and for an individual 's health when under duress. It should be noted that measurement of cognitive disturbances was not exact; the C-SOSI asks individuals to report cognitive impairments experienced as a result of stress, whereas measures of cognitive responding in the lab focused more on content of thoughts related to task performance. Therefore, the expected relation between the two measures was not clear. Cardiovascular reactivity was chosen as a specific measure of physiological responding because it has been linked with specific health outcomes, among them hypertension and heart disease (Krantz \& Manuck, 1984). Although a broader range of physiological measures of stress 
responding is desirable, the availability and cost associated with collecting a variety of parameters limits their consideration for conducting the proposed study. Finally, behavioral responses to stress (e.g., increased substance use, avoidance behaviors, seeking social support) were not measured, primarily because many of these responses likely would not be observed during a laboratory-based stress induction procedure.

In the second part of the study, participants were instructed in a stress reduction technique, which they were asked to practice for two weeks. To this end, the study sought to test the specificity hypothesis by examining the utility of the C-SOSI subscales for predicting adherence to the technique based on the participants ${ }^{\text {ee }}$ stress response profiles. According to prior empirical work (Rausch et al., 2006; Schwartz et al., 1978), an individuales typical stress response may be associated with both efficacy of a specific intervention and adherence to its regular practice. For example, if a certain stress reduction technique is hypothesized to operate via a reduction in negative thinking, it may prove more clinically expeditious to recommend this technique first to a patient who experiences significant cognitive stress responses. Behaviorally speaking, the stress management technique that provides the most immediate escape from aversive stimuli should serve as a more salient negative reinforcer and, therefore, be more likely to be used again. The current study tested this ,,specificity ${ }^{\text {ee }}$ hypothesis. As few other studies have examined the ,specificity ${ }^{\text {ee }}$ hypothesis, and none have used recently validated measures of stress responding, it was difficult to predict what the results may be. Early research in this area yielded mixed results, and, unfortunately, the line of research was not continued to substantiate any support for the ,specificity ${ }^{e e}$ hypothesis (Carrington, 1993). However, building on the work that has been done, it was expected that individuals engaging in any stress reduction technique would experience an overall amelioration of all symptoms of stress. Additional benefits may be seen by 
matching type of stress response to type of stress management selected. However, it was unknown whether these differences would occur in amount of practice, perceived effectiveness of the technique, or enjoyment of the technique. Any differences that were found would support the ,specificity ${ }^{\text {ee }}$ hypothesis, which would indicate the utility of assessing a patient ${ }^{\text {ee }}$ stress response profile prior to making recommendations regarding type of stress reduction technique.

Due to its broad inclusion in numerous stress management programs, a diaphragmatic breathing technique was chosen as the intervention technique to be examined in the current study. Though breathing is an action that most people do without much thought, its importance in stress reduction is undeniable. Most stress reduction techniques (e.g., yoga, meditation, cognitive behavior therapy for panic disorder) employ diaphragmatic breathing as part of daily practice. Fried (1993) underscores the importance of breathing, especially during times of stress, and the deleterious side effects that may result when too little attention is paid to this lifesustaining action. According to empirical work on the importance of breathing within stress management programs, typical stress responding (via the fight-flight reaction) involves rapid, shallow breathing that involves significant chest movement (Davis, Eshelman, \& McKay, 2008). In contrast, slow, deep breathing from the diaphragm is more closely linked with the relaxation response. Although chest breathing results in rapid inhalation of oxygen needed for the body to respond with a healthy fight-flight reaction in cases where an individuales life is in danger, this amount of oxygen is not typically needed to respond to the types of stressors most individuals encounter on a daily basis. For example, increased oxygen uptake and the associated adrenocortical arousal that follows is not required to cope with a traffic jam or responding to an irritating telemarketer. In most cases, the stress response results in an over-perfusion of oxygen, a physiological state that diaphragmatic breathing is designed to correct. It follows that adopting 
a focused breathing practice could lead to positive outcomes across all stress response domains, but perhaps most noticeable within the physiological domain. In the present study, participants were taught a standard diaphragmatic breathing stress management technique and asked to practice it regularly for two weeks.

Method

\section{Participants}

Participants were 70 undergraduate students in psychology courses (79\% female, $91 \%$ White, $4 \%$ Black, $M$ age $=21.2$ years, $S D=6.01)$. The gender and racial demographic characteristics of the current sample are representative of the population in undergraduate psychology courses at West Virginia University. Using the robust effects reported in Schwartz, Davidson, and Goleman (1978) as guidance, a more conservative effect size of .30 was entered into GPower version 2.0 (Erdfelder, Faul, \& Buchner, 1996). With three predictors in a regression analysis, this yielded a necessary sample size of 62. As there was only one stress management technique being tested in the current study, as opposed to two techniques in Schwartz and colleagues ${ }^{\text {ee }}(1978)$ study that employed 77 participants, this sample size was judged to be adequate. Only non-smokers were invited to participate, as nicotine affects cardiovascular reactivity and may introduce an additional source of error variance. Students who reported using medications that affected measures of cardiovascular functioning (e.g., betablockers, anxiolytics) also were excluded due to the interference of these substances upon measures of cardiovascular reactivity. Students also were excluded from participation if they reported experiencing a history or presence of asthma or panic attacks, as attention to breathing may interfere with their perceived benefit or enjoyment of the technique, potentially affecting adherence data. Finally, students were excluded from participation if they were already regularly 
practicing a relaxation technique (more than one hour per week), as it may influence adherence data. Of the 389 students who completed the demographic screening questionnaire, 186 met study inclusion criteria and were invited to participate in the lab portion. Of those invited, 70 scheduled and attended lab appointments; the remaining 116 either declined to schedule an appointment or failed to attend their allotted times (see Figure 1 for flow of participants). Individuals who participated in the lab session and those who declined the invitation to participate were compared with one another using $t$ tests for the continuous variable (age) and $\chi^{2}$ tests for the remaining categorical variables (see Table 1). No group differences were observed. In the second part of the study, 46 of the 70 participants submitted at least one online daily questionnaire indicating their use of the breathing technique. Sixteen participants responded to the final follow-up contact.

\section{Measures}

Demographic Information. Participants were asked to report their personal health history, current medication and substance use, and family health history. Other basic demographic information also was gathered (see Appendix A).

Calgary Symptoms of Stress Inventory (C-SOSI; Carlson \& Thomas, 2007). The Calgary Symptoms of Stress Inventory was developed with a mindfulness-based theory as a guide. It is composed of 56 items that assess how an individual responds to stressors. Participants were asked to indicate on a scale of 0 to 4 how often they experience each symptom when presented with a stressor (with $0=$ Never and $4=$ Very Frequently). The items were factor analyzed by the instrument ${ }^{e e}$ s authors, and eight factors were found. According to the authors, Cronbach ${ }^{\text {ee }}$ alpha for the whole scale was .95 and ranged from .80 to .92 for the various factor-derived subscales. The Depression subscale of the C-SOSI was shown to be significantly correlated with the Profile 
of Mood States (POMS) Depression subscale and Total Mood Disturbance scale, the C-SOSI Anger subscale was found to be significantly correlated with the POMS anger subscale, and the Cognitive Disorganization subscale of the C-SOSI was significantly correlated with the POMS Confusion subscale. In addition, the C-SOSI total score was positively correlated with the POMS Total Mood Disturbance score and negatively correlated with the European Organisation for Research and Treatment in Cancer Quality of Life Questionnaire (Carlson \& Thomas, 2007). Means, standard deviations, and Cronbach 's alphas for the scales measured in the current study are presented in Table 2.

Multiple Affect Adjective Checklist-Revised (MAACL-R; Zuckerman \& Lubin, 1985). The short version of the MAACL-R was used to assess affective responses during the laboratory tasks used in this study. Participants indicated their emotional state by choosing among a selection of 66 adjectives upon completion of the task. The short version of the questionnaire is comparable to the full-length checklist (which employs 132 adjectives) in regard to reliability and validity, which has been shown to be acceptable. For example, internal consistency alphas range from .86 to .96 for the various subscales of the MAACL-R (Lubin, Van Whitlock, Reddy, \& Petren, 2001). There are three subscales comprising negative affect on the MAACL-R: Depression, Anxiety, and Hostility. These three subscales were summed to arrive at an overall measure of Negative Affect, which was used in conjunction with the Positive Affect subscale to measure the range of affective responding to the stress presentations in this study. Convergent validity for the three subscales of negative affect has been demonstrated using measures of state depression, anxiety, and anger, respectively, and with the negative affect subscale of the Bradburn Affect Balance Scale (ABS; Lubin et al., 2001). The Positive Affect subscale of the MAACL-R has been shown to be correlated with the positive affect subscale of the ABS. In the 
present study, Cronbach's alphas for the Negative Affect subscale were .83 and .85 following the grip and arithmetic tasks, respectively, and for the Positive Affect subscale were .67 following the grip task and .73 following the arithmetic task.

Brief Coping Orientations to Problems Experienced (Brief COPE; Carver, 1997). The COPE was devised as a dispositional measure of coping with stressful situations (Carver, Scheier \& Weintraub, 1989). However, it has also been used to rate reactions to specific stressors. The authors report that internal consistency for the COPE when used as a situational measure is higher than that when it is used as a dispositional measure (ranging from .45 to .92 for the dispositional version; Carver, Scheier \& Weintraub, 1989). Carver (1997) reported that the Brief COPE was a more refined version of the full COPE, with more coherent scales. Internal consistency reliabilities for the Brief COPE have been shown to range from .50 to .90 (Carver, 1997). The Brief COPE is comprised of 28 items making up 14 scales that assess different coping strategies. Participants were asked to rate on a 0-3 scale how frequently they used a variety of cognitive coping strategies during the experimental tasks. Kershaw and colleagues (2008) found evidence for two factors using the Brief COPE: an Avoidance factor and an Active Coping factor. Subscales of the Avoidant factor include Denial, Self-Distraction, Behavioral Disengagement, Venting, and Blame. The Active Coping factor is comprised of the use of Emotional Support, Positive Reframing, Active Coping, Planning, Acceptance, and Support Seeking subscales. In previous research, a similar Avoidant factor from the full COPE was associated with greater levels of anxiety (Geirdal \& Dahl, 2008). In the present study, Cronbach 's alphas for the Avoidant factor were .78 for the grip task and .81 for the arithmetic task; for the Active Coping factor, alphas were .83 for the grip task and .79 for the arithmetic task. 
Cognitive anxiety. Cognitive responses to lab stress were assessed using the cognitive anxiety subscale of a recently developed performance anxiety measure (Cheng, Hardy, \& Markland, 2009). The instrument was designed to measure worry and self-focused attention as components of anxious responses to sport performance-related stress. Cognitive anxiety was supported as a distinct factor in confirmatory factor analysis of the instrument (Cheng et al., 2009). Cronbach ${ }^{\text {ee }}$ alpha for the 11 cognitive anxiety items was .85 in the scale development study. However, as studies of construct validity have not yet been completed, the instrument was used only for exploratory purposes. Alphas for the current study were .88 following the grip task and .93 following the arithmetic task.

Daily questionnaire. Participants were asked to complete a daily questionnaire about their experiences practicing guided breathing (see Appendix B). Once per day over a two-week period, they reported their overall daily stress level, types of stressors faced, pre-practice and post-practice stress level, enjoyment of the stress reduction technique, effectiveness of technique, and barriers to practice (if applicable). Mean scores for the responses to each item are presented in Table 3. The questionnaire was submitted electronically, via a website created for the study.

Cardiovascular apparatus. Heart rate was measured continuously using a Polar heart rate monitor model s810i (Finland) that uses an elastic strap containing two electrodes. The strap was worn around the midsection of the chest such that the electrodes were positioned directly over the heart. Heart rate signals were transmitted via a wristwatch recorder to a Dell computer where the data were stored. Blood pressure was measured every two minutes via an IBS SD-700A automatically-occluding sphygmomanometer (Waltham, MA). This device contains a microphone embedded in an occluding cuff for detecting Korotkoff sounds. The cuff was set to 
inflate to $150 \mathrm{mmHg}$ and deflate at the rate of $3 \mathrm{~mm} / \mathrm{sec}$. Blood pressures were displayed digitally and recorded by the experimenter.

\section{Procedure}

Participants were asked to refrain from consuming alcohol or caffeine and to avoid exercising for three hours prior to their lab visit; this was confirmed verbally upon arrival to the research session. After obtaining informed consent, participants were outfitted with the heart rate monitor as described above and height and weight were measured. Next, they completed the CSOSI, and the blood pressure cuff was placed on their left arm. There was an initial 15-minute rest period to allow the participant to become accustomed to the surroundings and apparatus. Resting measures of heart rate and blood pressure were taken during the final five minutes of this period, with the heart rate measurement being collected on a beat-to-beat basis and blood pressure obtained every two minutes. After resting physiological measurements were obtained, participants began the laboratory stressors. The first task involved an isometric hand grip task; this task required the participant to reach his or her maximum level of grip strength using a Lafayette Instruments hand dynamometer (Model 78010; Lafayette, USA). The participant then held the dynamometer at 30 percent of his or her maximum capacity for three minutes. Heart rate was measured continuously and blood pressure was taken during mins 1 and 3. Measures of state affect and cognitive response were obtained following task completion; during this time, measures of heart rate and blood pressure recovery also were gathered. Following a five minute recovery period, the second stressor task was conducted. During the second task, participants were asked to perform a mental arithmetic challenge; this involved subtracting by sevens from 9000 for three minutes. Heart rate and blood pressure measurements were collected as in the first 
stressor task. A second five minute recovery period ensued, with measures of physiological, affective, and cognitive responding being collected as in the first recovery period.

Upon completion of the laboratory stressors, participants were given a brief introduction to the diaphragmatic breathing technique. Instruction included a rationale for a regular relaxation practice and the specifics of diaphragmatic breathing (see Appendix C). Participants practiced the technique during the session to ensure accuracy of breathing diaphragmatically. During the final five minutes of practice, HR was measured continuously and one measure of BP was obtained at min four. Participants ${ }^{e e}$ expectations for the benefit of a regular relaxation practice were collected upon conclusion of a practice breathing session. The apparatus was then removed, and participants were given information about the study, including information for a website designed to guide them through the breathing practice and allow them to submit the daily questionnaire. An e-mail was sent at the end of one week to remind the participants to complete the daily log on the website, and again at the end of the second week to notify them of the completion of the study. Participants received course credit for time spent in the laboratory portion of the study; those who completed daily questionnaires over the two-week period were compensated with $\$ 10$. Finally, participants were contacted by e-mail for a six-week follow-up to assess whether or not they were still practicing the breathing technique. This procedure was approved by the West Virginia University Institutional Review Board.

Results

Data Reduction, Artifact Detection, and Preliminary Analyses

Data were analyzed using IBM SPSS Statistics 19 (Somers, NY). Using the criteria recommended by Marler, Jacob, Lehockzy, and Shapiro (1988), BP data were cleaned by examining outliers, the difference between SBP and DBP measurements in a single reading, and 
overall differences between readings. Systolic blood pressure greater than 250 or lower than 70 were removed from the data set; this resulted in one measurement being removed. Diastolic blood pressures greater than 150 or lower than 45 also were removed (39 measurements or 5.6\% of all DBP measurements); removed DBP data were replaced with gender- and period-specific mean values (female: $M=70 \mathrm{~mm} \mathrm{Hg}$ for grip task, $M=69 \mathrm{~mm} \mathrm{HG}$ for math task, and $M=67$ $\mathrm{mm} \mathrm{Hg}$ for rest periods; male: $M=75 \mathrm{~mm} \mathrm{Hg}$ for grip task, $M=70 \mathrm{~mm} \mathrm{Hg}$ for math task, and $M$ $=67 \mathrm{~mm} \mathrm{Hg}$ for rest periods). A single cardiovascular reactivity criterion variable (sympathetic activity) was calculated by aggregating residualized change scores using the parameters of HR, SBP, and DBP across the two tasks. This process involved regressing task values of each cardiovascular parameter onto their respective resting values for each of the two tasks; the standardized residual scores for each of these analyses were saved and an aggregated measure of cardiovascular reactivity was calculated by averaging standardized residual change scores for HR isometric task, SBP isometric task, DBP isometric task, HR math task, SBP math task, and DBP math task. For purposes of this calculation, HRs from the blood pressure monitor were used because equipment problems associated with the Polar monitor yielded missing data for 37 (53\%) study participants.

Autonomic activity also was assessed using two relatively common measures of HRV: low frequency (LF) HRV and high frequency (HF) HRV. LF HRV has been shown to reflect both sympathetic and parasympathetic activity, whereas HF HRV is thought to be a pure measure of vagal (parasympathetic) tone (Berntson et al., 1997; Thayer, Peasley, \& Muth, 1996). The ratio of LF to HF HRV has been hypothesized to represent sympathetic tone (Haensel et al., 2008). Both LF and HF HRV were determined using HR data collected from the Polar heart rate monitor. Heart rate data were transferred from the Polar monitor to the Kubios HRV analysis 
software version 2.0 (University of Kuopio, Finland) for purposes of spectral waveform analysis. Using the Kubios program, HR data were visually inspected for artifacts, with a low level of artifact correction being employed. Relative percent of LF and HF HRV (in $\mathrm{ms}^{2}$ ) within the autoregressive domain were analyzed, as these data are reported under the best fitting model (as determined by the Kubios program) to eliminate noise artifact (Berntson et al.,1997; Niskanen, Tarvainen, Ranta-aho, \& Karjalainen, 2002). LF and HF HRV values were log transformed before being submitted to regression analyses (Sandercock, 2007). Due to missing HR data, autonomic indices were calculated on only 33 (47\%) study participants.

The data from all self-report measures were screened for missing items, normality, and presence of outliers prior to analyses. The only questionnaire with missing items was the COPE, in which three participants missed 11 of the 28 items (these items were on the back of the response page); for these three cases, items were replaced using mean imputation. Moderate positive skew was found for the computed physiological subscale of the C-SOSI (skew $=3.01$, kurtosis $=0.87)$; it was corrected using a square root transformation ( $\mathrm{skew}=-0.36$, kurtosis $=$ 0.07). Additionally, significant positive skew was observed for the positive and negative affect subscales of the MAACL-R (skew = 8.54 and 7.02, respectively; kurtosis = 11.73 and 2.38); they were corrected using a logarithmic transformation (skew $=1.58$ and -2.09 , respectively; kurtosis $=-1.09$ and 0.28). Descriptive statistics for each of the remaining self-report scales approximated a normal distribution. Mean scores for all study variables are shown in Table 4.

Adherence data also was skewed $($ skew $=5.07$; kurtosis $=1.35)$; as such a logarithmic transformation of the sum number of days the participant practiced the technique (ranging from $0-14$ ) was conducted to normalize the distribution ( $\mathrm{skew}=.66$; kurtosis $=-1.01$ ). Ratings of amount of stress reduction experienced following practice of the technique (calculated using a 
residualized change score for pre- to post-practice daily ratings of stress), how helpful the participant found practice of the technique (ranging from 0-10), and enjoyment of practice (ranging from 0-10) were normally distributed. Twenty-four participants did not provide any ratings for stress reduction, benefits, enjoyment, or amount of practice and, thus, were not included in adherence analyses.

Correlations among dependent variables. Relations between dependent variables were examined using Pearson correlation coefficients (see Table 5). Significant correlations were observed among cognitive anxiety, affect, and coping responses, between affect and coping, and between HR and HRV. Specifically, cognitive anxiety was correlated positively with both active and avoidant coping, suggesting that higher levels of anxiety were associated with higher coping responses. Cognitive anxiety also was correlated positively with negative affect and correlated negatively with positive affect. Active coping was positively correlated with both avoidant coping and with negative affect, again suggesting that increased coping responses were utilized among participants experiencing more negative affect. Negative and positive affect were negatively correlated. Among the physiological measures, LF and HF HRV showed a robust negative correlation, as would be expected. HR was positively correlated with LF HRV and negatively correlated with HF HRV. Again, this would be expected given that HF HRV is thought to represent parasympathetic activity. Finally, SBP and DBP were positively correlated. Physiological variables were not correlated with any of the self-reported variables.

Sex Differences. As sex differences typically have been reported in physiological and affective responding (e.g., Allen, Stoney, Owens, \& Matthews, 1993; Whited \& Larkin, 2009), males and females comprising the study sample were compared on all study variables using independent samples t-tests (see Table 4). As expected, sex differences were observed for mean 
scores on SBP reactivity and affective responses. Specifically, males exhibited higher SBP responses and greater positive affect during the laboratory tasks. Other sex differences also were observed. Females reported experiencing more affective and physiological symptoms of stress on the C-SOSI, as well as more cognitive anxiety during the stressor tasks. Sex of participant was included as a covariate in regressions using these parameters. No sex differences were observed with respect to coping, negative affect, measures of physiological reactivity other than SBP, cognitive symptoms of stress, or number of days practicing diaphragmatic breathing.

Task Differences. Task effects were examined using paired samples t-tests. As shown in Table 6, participants exhibited higher BP and more avoidant coping during the hand grip task, but endorsed more negative affect and cognitive anxiety during the arithmetic task. No task differences were observed with respect to active coping responses, positive affect, HR reactivity, or HRV.

Primary Study Analyses: Examination of the relation between C-SOSI stress response scores and measures of observed laboratory stress responses.

Six hierarchical linear regressions were conducted to examine whether C-SOSI scores predicted cognitive, affective, and physiological responding to the laboratory stressors. In each regression, sex was entered in the first step and all three subscales of the C-SOSI (Cognitive, Affective, and Physiological Responding) were entered as independent (predictor) variables in the second step. Criterion variables were aggregated across tasks. Measures of multicollinearity (tolerance and VIF) and influence (Mahalanobis ${ }^{\text {ee }}$ distance) were inspected for each regression equation to assure that assumptions for each analysis were met.

Cognitive Response to Stress. Cognitive responding to stress as measured by the two subscales of the COPE (i.e., Avoidant Coping and Active Coping) were each examined using the 
hierarchical linear regression approach outlined above. Although the regression model was not significant for Active Coping, $F(4,65)=1.91, R^{2}=.10$ (see Table 7), a significant model was observed for Avoidant Coping in Step 2, $F(4,65)=4.43, p<.01, R^{2}=.21, \Delta R^{2}=.17$ (see Table 7). Review of the three C-SOSI subscales revealed that the C-SOSI Affect subscale was the strongest predictor in Avoidant Coping response to the experimental tasks, $\beta=.37$.

As an exploratory analysis, another measure of cognitive responding to stress was examined. This measure was developed recently to assess cognitive and physiological anxiety in response to performance demands among athletes (Cheng, Hardy, \& Markland, 2009). As shown in Table 7, this measure of cognitive stress response was predicted by the C-SOSI in Step 1 and Step $2, F(1,68)=6.75, p<.01, R^{2}=.09$, and $F(4,65)=6.38, p<.001, R^{2}=.28, \Delta R^{2}=.19$. There were no significant individual predictors.

Affective Response to Stress. Because sex differences were observed for affective response to stress, analysis of the two measures of affective response to stress (i.e., Positive Affect and Negative Affect) employed a hierarchical regression analysis with sex included in the first step of the equation, and the remaining variables entered in the second step. The analysis of Negative Affect yielded a significant effect for sex in Step $1, F(1,67)=8.81, p<.01, R^{2}=.12$, and also in Step 2 with the other predictors included, $F(4,64)=6.13, p<.01, R^{2}=.28, \Delta R^{2}=$ .12 (see Table 8). In the second step of the model, both sex and the C-SOSI Physiology subscale were significant predictors of Negative Affect $\left(p^{\text {ec }}<.05\right)$. Analysis of Positive Affect also showed a significant effect for sex, $F(1,68)=9.44, p<.01, R^{2}=.12$, and when including the other predictors, $F(4,65)=2.70, p<.05, R^{2}=.14, \Delta R^{2}=.02$ (see Table 8 ), sex was the only significant predictor, $\beta=.34$. 
Physiological Response to Stress. Finally, physiological responding was examined using a sum of the physiological subscales of the C-SOSI to predict cardiovascular reactivity to stress. Three separate regression analyses were conducted to examine (a) a summed measure of cardiovascular reactivity (across HR, SBP, and DBP), (b) LF HRV, and (c) HF HRV. In each regression, sex was included in the first step of the model, and the C-SOSI subscales were included in the second step. Significant models were not observed for either LF HRV or HF HRV, $F(4,51)=2.37, R^{2}=.16$, and $F(4,47)=1.25, R^{2}=.10$, respectively.

The aggregated cardiovascular reactivity variable (sum of SBP, DBP and HR change scores) was predicted by sex in Step $1, F(1,68)=7.06, \mathrm{p}<.01, \mathrm{R}^{2}=.09$, and when the C-SOSI scales included in Step 2, $F(4,65)=4.55, p<.001, R^{2}=.22, \Delta R^{2}=.13$ (see Table 9). Both sex and the C-SOSI Physiology subscale were significant predictors in the final model. To follow up on which component of cardiovascular reactivity might be associated with the C-SOSI Physiology and sex variables, each cardiovascular variable contained in the aggregated value (i.e., SBP, DBP and HR) was examined separately. Systolic blood pressure response to stress was predicted by sex alone, $\mathrm{F}(1,68)=9.23, \mathrm{p}<.01, R^{2}=.12$, and with the C-SOSI scales, $F(4$, $65)=4.11, p<.01, R^{2}=.20, \Delta R^{2}=.08$. Again, both sex and C-SOSI Physiology were significant predictors in the final model (see Table 9). No significant associations were observed between any C-SOSI subscale and either HR or DBP reactivity.

Examination of the relation between C-SOSI stress response scores and measures of adherence, enjoyment, and perceived effectiveness of the diaphragmatic breathing intervention

In the second part of the study, the aggregated subscales from the C-SOSI were used in four linear regressions predicting adherence to the stress management technique. The regressions

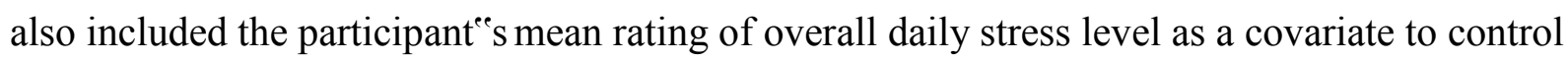


for individual differences in stress levels. None of the C-SOSI scales was associated with the number of days practicing diaphragmatic breathing, $F(4,41)=.73, R^{2}=.07$ (see Table 10). Additionally, regression analyses for enjoyment of practice, perceived benefits of practice, and amount of stress reduction were not significant, $F(4,34)=.58, R^{2}=.06, F(4,34)=.48, R^{2}=$ .05 , and $F(4,34)=.94, R^{2}=.10$, respectively (see Table 10$)$.

To explore the relation between actual stress responses to the laboratory tasks and adherence to the use of the breathing technique, the four linear regressions were re-analyzed using lab responses (i.e., aggregated physiological change, affect, and coping responses) rather than self-reported stress responses (i.e. C-SOSI scales) as predictor variables. Perceived benefit of the technique, amount of stress reduction post-practice, and days of practice were not predicted by the model (see Table 11). However, the model was significant for ratings of enjoyment of the technique, $F(5,33)=2.88, p<.05, R^{2}=.30$. Physiological reactivity was the only significant predictor in the model, $\beta=.33$.

To further explore the relations among variables, the adherence variable was coded as a dichotomous variable, such that no days of practice $=0$ and one or more days of practice $=1$. A total of 39 of the 70 participants reported practicing the breathing technique at least once, but 31 of them did not practice even once. Seven of these 31 participants submitted questionnaires reporting nonadherence; the remaining participants did not provide any adherence data. These two groups were then compared on measures collected during the laboratory session using independent sample t-tests. Similar to the regression analysis above, participants who scored higher on the Active Coping subscale of the COPE in response to the laboratory stressors were marginally more likely to be in the "practice" group than those who failed to practice the exercise even once, $t(68)=3.82, p=.055$. No other variables distinguished those who practiced 
from those who did not practice the stress management technique. At six-week follow-up, 11 participants indicated that they had practiced the diaphragmatic breathing since their participation in the study, and five reported that they had not practiced; the remaining 54 participants did not respond to the prompt for information.

Qualitative data (i.e., type of daily stressors, barriers to practice) also were examined. Types of daily stressors were coded into three categories: school/work, interpersonal stress, and physical health problems (e.g., illness, insomnia, pain). Of these, the majority of stressors reported were school/work (52\%); an additional 24\% were related to interpersonal issues, and $24 \%$ to physical health problems. The most frequently reported barriers to practicing the relaxation technique were not having enough time/having other things to do (38\%) and not having stress/not feeling the need to practice (37\%). Other reported less frequent reasons that participants did not practice included forgetting, feeling sick or tired, not having internet access, and not wanting to practice.

\section{Discussion}

The primary aims of the current study were to provide evidence of construct validity for a measure of stress responding, the C-SOSI, and to explore the clinical utility of the measure in predicting adherence to practice of a stress management technique. It was hypothesized that participants $^{\text {ee }}$ self-reported stress response profile would mirror their observed responses when confronting laboratory stressors. Additionally, based on the specificity hypothesis proposed by Schwartz and colleagues (1978), it was hypothesized that participants responding to stress primarily within the physiological domain would be more likely to practice the stress management technique over a two-week period. 


\section{Construct Validation of the C-SOSI}

In the lab-based portion of the study, several subscales of the C-SOSI were associated with participants ${ }^{e e}$ actual stress responses. However, the relations were not all as hypothesized. The Affect scale from the C-SOSI (a composite of Anger and Depression subscales) explained some variance in participants ${ }^{\text {ee }}$ cognitive responses, as measured by the Avoidant Coping subscale of the COPE. Additionally, participants ${ }^{\text {ee }}$ systolic blood pressure reactivity and overall cardiovascular reactivity were associated with the Physiology scale (a composite of several CSOSI subscales related to physiological responses to stress). Finally, the C-SOSI physiology subscale also explained variance in affective responding to the two tasks. Each finding will be discussed in turn.

Cognitive Responses. To validate the C-SOSI, the Cognitive Disorganization subscale was expected to explain unique variance among measures of cognitive response to laboratory stress presentations. However, the Cognitive Disorganization subscale was not associated with either measure of cognitive responding utilized in the lab session. In contrast, avoidant coping responses were associated with responses on the C-SOSI Affect subscale. Thus, cognitive responding in the lab did not necessarily mirror cognitive responses to stress experienced in daily life among study participants. However, it is possible that cognitive responding in the lab was not adequately captured by the measures utilized. As such, findings may not necessarily indicate limited validity of the C-SOSI, but instead may be a function of the instruments chosen to assess cognitive responding, suggesting that they may not have been the best tools with which participants could report their cognitive behavior in the lab. As previously noted, one measure (the C-SOSI) represented symptoms of cognitive impairment whereas lab measures represented content of cognitions related to task performance. As such, this discrepancy involved 
measurement of different traits at different times. As noted by Cone (1978) different methods of measurement exert a strong influence on assessment of a construct; this most certainly was a limitation in the current study. Additionally, although situational and dispositional coping have been correlated in some studies, there also is evidence that coping responses are situationally dependent and are based on cognitive appraisals of the stressor (e.g., goodness-of-fit hypothesis) (Lazarus \& Folkman, 1984; Ptacek, Pierce \& Thompson, 2006). In the present study, different aspects of cognitive responses were assessed situationally and in a more dispositional manner. Specifically, asking participants to report on cognitive symptoms in response to real life stress experienced over a two-week time period (as was done in the present study via the C-SOSI) represents a different assessment strategy than asking them to report cognitions experienced immediately following contrived laboratory stressors. In this regard, the relation between dispositional and situational ratings of similar constructs is predictably far from perfect.

Cone (1978) also noted that cognitive facets are difficult to capture and may represent "a more basic emotion, e.g. fear or anxiety" (p. 883). To the extent that commonalities exist between measures of cognition and emotion, it was not surprising that a participant ${ }^{\mathrm{e}} \mathrm{s}$ tendency to react emotionally, as evidenced by C-SOSI Affect subscale scores, influenced the type of thinking he or she has during engagement in laboratory stressors. Additionally, both cognitive and affective responses are obtained via self-report assessments, and use of this shared measurement approach is likely to enhance correspondence between these two measures.

In addition to reasons why this analysis resulted in findings that were not hypothesized, there are potential explanations for the veracity of the results. For example, there is prior empirical support for a relation between negative affect and avoidant coping (Eaton \& Bradley, 2008), and, in fact, avoidant coping is often thought to represent a type of emotion-focused 
coping (Folkman \& Moskowitz, 2004). One study of cognitive behavioral stress management indicated that although some forms of avoidant coping (e.g., denial) may reflect effective ways of regulating negative emotion acutely, continued reliance on this type of coping was associated with increased negative affect over time (Carrico et al., 2006). Thus, because the C-SOSI Affect subscale predicted cognitive responses to stress, these results could be viewed as aligning with previous research in the stress and coping literature. This is further supported by the significant correlations observed among variables in the present study, particularly the observed associations among cognitive anxiety, negative affect, and coping responses. Avero and Calvo (1999) also have reported concordance among the response domains of cognition and affect, particularly when reactivity is elevated.

In interpreting the affect-cognitive relation observed in the current study, it is also worth considering the types of items that comprise the Cognitive Disorganization subscale of the CSOSI. Some of the items focus on doing things slowly, getting confused or mixed up when asked to do things quickly, and having difficulties concentrating, but other items involve having fearful thoughts. This may account for the fact that the Cognitive Disorganization subscale had the lowest internal consistency reliabilities among all of the C-SOSI scales. None of the items on this subscale tap into the types of thoughts most likely to occur during presentation of the types of laboratory stressors used in this study (e.g., "I"m not doing well," "What will the experimenter think about my performance?"). In this regard, it is not all that surprising there was a lack of correspondence between score on the C-SOSI Cognitive Disorganization subscale and the measures of cognitive response to stress in the laboratory.

Affective Responses. Although the C-SOSI Affect subscale was associated with avoidant coping and cognitive anxiety in the lab, it was not related to affective responses in the lab as 
measured by the MAACL-R. However, the C-SOSI Physiology subscale was related to affective responding to the lab stressors. Again, although this relation was not hypothesized, it was not entirely unexpected. Given Folkman and Lazaruse (1991) definition of emotions as including physiological and cognitive components, some shared variance would be expected between affective responses to stress and their underlying cognitive and somatic/physiological components. Pollatos and colleagues (1995) also reported significant associations between physiological and emotional responses to stressors. Thus, it appears that the physiological and emotional components of anxiety are indelibly linked, and that this association occurs not only acutely but also with repeated exposure to stressors (McEwen, 1998).

The observed association among reports of physiological symptoms of stress and negative affect is very interesting. Both increased negative affect and reports of poor health have been reported in individuals scoring higher in neuroticism (Goodwin \& Friedman, 2006; Hamid, 2004). However, as neuroticism was not measured in the present study, this association cannot be explored using the current data. It is interesting to note that reports of somatic symptoms of stress were positively associated with both negative affect and cardiovascular reactivity during the lab stressor, implicating a direct pathway between participants ${ }^{\text {ee }}$ responses to stress and health outcomes. Negative affect consistently has been associated with poorer immune function and health outcomes (Friedman \& Booth-Kewley, 1987; Segerstrom, 2000), and the cardiovascularneuroendocrine response is thought to be the mechanism through which this relation occurs. Likewise, state positive affect has been associated with fewer self-reported illness symptoms; although a stress-buffering hypothesis has been offered, the direct pathophysiological process for the salubrious effect of positive affect is unknown (Pressman \& Cohen, 2005). Neuroendocrine/immune parameters were not collected in the present study, and no relation 
between cardiovascular reactivity and affective response was observed, so these findings cannot illuminate the link between negative affect and health in terms of physiological mechanisms. However, the present study does provide further evidence for an association between acute affective responses to stress and longer-term health consequences.

Physiological Responses. As predicted, C-SOSI Physiology was related to cardiovascular reactivity to the lab stressors. This is an impressive finding, given that laboratory and ambulatory measures of cardiovascular reactivity have not always been congruent (e.g. Fahrenberg et al., 1993; Van Egeren \& Sparrow, 1989), and further variability is introduced into the current measurement of the stress response by utilizing a multi-method approach (i.e., paperand-pencil self-report vs. physiological monitoring; Cone, 1978). Previous research that has examined the correspondence between self-reported stress and actual physiological responses to stress has been plagued by instrument limitations (Avero \& Calvo, 1999). In contrast to the more general measures of stress used in previous studies, the current study employed a subscale comprised of items tapping a full range of symptoms across various organ systems. Interestingly, when such an instrument was used in the current study, a significant correspondence between self-reported physiological stress responses and actual physiological stress responses was detected. Given that assessment of actual patterns of physiological stress responses requires purchase of recording instrumentation and engagement in somewhat lengthy laboratory protocols, it is noteworthy that the C-SOSI Physiology subscale was shown to exhibit some construct validity in explaining variance associated with actual physiological stress responses. In clinical settings, then, where assessments need to be relatively brief, the application of self-report methods of assessment may obviate the need for more extensive laboratory protocols typically used for assessing individual differences in physiological response to stress. The current study 
validates perhaps the most important parameter of an individuales stress response profile. Although both cognitive and affective responses to stress are associated with health outcomes, it is the physiological response to stress that is often considered the mechanism through which cognitive and affective stress responses exert their negative effects on health. In this regard, the C-SOSI Physiology subscale shows promise.

The present study is also pertinent in providing further evidence for the importance of the acute physiological response to stress in predicting poor health endpoints (e.g., the mechanism proposed by McEwen, 1998, and many others). However, support for this mechanism may be controversial, as recent research has indicated that greater cardiovascular reactivity is not consistently linked to poor health (De Rooij \& Roseboom, 2010). Clearly this will be an area of ongoing research, as investigators strive to explain the mechanisms through which stress reactivity impacts health. It is possible that the myriad symptoms included as items in the CSOSI, and the coverage of multiple physiological domains of responding (e.g., cardiopulmonary, upper respiratory, etc.), provide a better measurement of physiological responding to stress than previous instruments have offered and can be utilized in continuing research regarding stress and health.

In sum, the present study provides some construct validation for the C-SOSI, particularly the Physiology subscale. Although a limited number of physiological responses in the lab were congruent with participants ${ }^{\text {ee }}$ self-reported somatic experiences in response to stress, associations between self-reported measures of cognitive and affective domains were less impressive. As indicated in the description of conceptualizations of stress included in the study introduction, it may be difficult if not impossible to isolate each distinct response domain (Cohen \& Rodriguez, 1995; Folkman \& Lazarus, 1991). Further research with more sensitive measures of affect or 
cognition, if they exist, may help to clarify the degree to which these response domains overlap. However, it may be equally likely that the overlap in response domains would be observed regardless of the measures utilized. Provided that the observations can be explained by supported theories, it may not be necessary to isolate each domain but may be more useful to consider the constellation of stress responses experienced by an individual.

\section{Examination of the Specificity Hypothesis}

In the second part of the study, outcomes of adherence to a stress management technique (i.e., number of days practiced, enjoyment and benefit ratings, reduction in stress) were examined in relation to participants ${ }^{\text {ee }}$ self-reported stress response profiles. No significant relations emerged when using self-reported symptoms of stress, failing to support the use of the C-SOSI as a tool for identifying patients who would respond best to the breathing relaxation strategy used in this study. The physiological subscales of the C-SOSI were hypothesized to predict outcomes to a physiological stress management technique if indeed the "specificity" hypothesis is true. Given that the Physiology subscale is composed of a wide range of physiological symptoms from various organs in the body, it may prove beneficial to explore a measure that samples symptoms specifically associated with the stress management strategy being examined. Because the relaxation method used in the current study focused on changing respiration rate and depth, perhaps only items sampling those domains would predict adherence related outcomes associated with breathing relaxation programs. By including the full range of symptoms across numerous organ systems, as was done in the current study, any predictive validity of the instrument may be obfuscated. Examination of the five symptom domains (Muscle Tension, Cardiopulmonary Arousal, Sympathetic Arousal, Neurological/Gastrointestinal Symptoms, and Upper Respiratory Symptoms) comprising the Physiology scale of the C-SOSI, 
however, yielded no significant correlations with any measure of adherence in the current study, failing to find support for using this approach. Additionally, it is unclear if all of the symptoms included in the scale are applicable for the sample used in the current study. Thus, a fundamental examination of the scale and its psychometric properties for use with healthy samples of young adults may need to be conducted before exploring its utility in the prediction of adherence to stress management in this population. However, it also is possible that effects of stress reduction techniques are not dependent upon an individual ${ }^{\text {ee }}$ s stress response, and, therefore, the specificity hypothesis is not valid. If this were true, specific measurement and categorization of an individuales stress response profile would be irrelevant and unnecessary.

Interestingly, cardiovascular reactivity in the lab, a more specific measure of physiological responding to stress, was associated with higher ratings of enjoyment of the breathing relaxation technique used in this study. In this regard, persons exhibiting the greatest cardiovascular reactions to the laboratory stressors enjoyed the relaxation practice the most. Although neither greater reductions in stress nor days of practice were associated with enjoyment of the technique, this finding provides some support for one aspect of the specificity hypothesis. Perceived enjoyment of behaviors has been indicated as an important component in intentions to engage in those behaviors (Lawton, 2009); thus, it is significant that highly reactive participants reported enjoying actual engagement in the desired behavior, even if they did not practice more or report better outcomes. The extent to which increased enjoyment translated into improved adherence and efficacy is unknown if the follow-up period were extended beyond two weeks.

Coping responses observed in the laboratory also were associated with measures of adherence, such that those employing active coping in the lab reported greater enjoyment of the technique and were slightly more likely to practice the technique than those reporting less active 
coping during stress presentations. There is some previous empirical support for the observation that individuals with an active coping style are more likely to follow treatment recommendations, while those who adopt avoidant coping strategies are less likely to be adherent (Vyavaharkar et al., 2007; Weaver et al., 2005). However, replication of these findings is needed in order to place any confidence in them for use in clinical settings.

In reviewing the literature on matching patients to treatment, Mattson and Allen (1991) reported a plethora of client variables that have been examined. These included demographic characteristics, sociocultural characteristics, other personality and social variables (e.g., personality types, social support), features of the issue being treated, and psychopathology-based matching. A few of these variables were tested in the present study, though none predicted adherence to "treatment." Mattson and Allen concluded that matching research is filled with methodological challenges, many of which were encountered in the present study as well.

Finally, it is interesting to note that in a qualitative analysis of barriers to practice, the inability to make a time commitment was endorsed most frequently as a reason not to practice. If this finding is approached in terms of a cost-benefit analysis, the benefits of practice (which did not emerge as significantly associated with any predictor variable) did not outweigh the cost of the time it would take to practice and, thus, appropriately explains non-adherence (Lamiraud \& Geofford, 2007). This finding can further be considered in terms of delay discounting, in which the immediate benefits of practice (which presumably were low in comparison to other immediate payouts) were not preferable to the long-term benefits of a regular stress management practice. 


\section{Limitations of the Present Study}

Factors that complicated the current investigation included (a) difficulties with the collection of HRV data, (b) failure to include measures of perceived stress, effort, or performance during the laboratory tasks, (c) the range of items used to measure "cognitive" response to stress both in and out of the laboratory, (d) unknown psychometric attributes of CSOSI in an undergraduate student sample, and (e) participant attrition. Each will be addressed below.

Although two physiological recording instruments were utilized in the current study to measure HR, instrumentation problems with the Polar HR Monitor resulted in a large amount of lost data. Therefore, HRs from the IBS sphygmomanometer were used in the primary analyses in this study. Although HRs from the Polar Monitor have been shown to measure beat-to-beat cardiac cycles reliably (Goodie, Larkin, \& Schauss, 2000), HRs from the IBS device are known to be less accurate, primarily because they can only be measured during the $20-30$ sec period of time during which measures of blood pressure are being obtained. Continuous HR recording is required to examine $\mathrm{HRV}$, and because it was obtained on only about half of the participants, there was limited power in the current study to examine relations with either measure of HRV. Because LF HRV reactivity was marginally associated with C-SOSI Physiology scores, it is possible that with a complete data set, a significant difference may have been observed, adding more support to the validity of the C-SOSI Physiology for detecting sympathetic and parasympathetic reactions comprising the stress response.

Measurement of cognitive responses to stress also was problematic. Although the anxiety instrument was developed to measure cognitive aspects of anxiety (Cheng et al., 2009), it is a relatively new instrument and may require further studies to support its validity and reliability in 
that endeavor. As the cognitive anxiety measure was developed to assess anxiety with respect to performance (Cheng et al., 2009), and as errors in performance have been associated with increased anxiety (Avero \& Calvo, 1999), a direct measure of errors or effort (i.e., task performance) would have enabled an assessment of how much of the variance of the cognitive response to stress could be explained by task performance or engagement. The cognitive response domain also could have been better measured by including an assessment of appraisals of the tasks, as several researchers have noted that the stress and coping process begins with an appraisal of threat (Beck, 1993; Folkman et al., 1986). Equivalent measures of cognitive responding were not tested, as one instrument used represented measurement of stress-related cognitive impairment and other instruments represented content of thoughts related to task performance. Therefore, the measurement of cognitive responses was not sufficient to adequately test the construct validity of the Cognitive Disorganization subscale of the C-SOSI. The observed association between affect and cognitive anxiety may have been better explained by participants ${ }^{c e}$ appraisals of the stressfulness and/or difficulty of the tasks in which they engaged.

It should be noted that the C-SOSI has not been normed on a sample equivalent to that used in the present study. Thus, it is unclear whether the factor structure employed to derive the Physiology, Affect, and Cognitive subscales used in this study would be similar to the factor structure of the instrument when it was completed by healthy young adults instead of cancer patients participating in a mindfulness intervention. Future empirical work on the factorial validity of the C-SOSI will be needed to determine the stability of the factor structure on samples of healthy young adults and the extent to which these differences affected the results of the present study. 
The present sample also limits generalizability of findings. As participants were healthy young adults who likely were not actively seeking stress management treatment (i.e. individuals with panic disorder or who were already engaged in stress reduction programs were excluded), the results should not be translated to clinical populations without caution. Clearly, those who seek treatment for stress-related problems would be more motivated to engage in regular practice than the sample employed in the current study.

Using a convenience sample of undergraduate students may also have posed problems for follow-through and engagement in regular stress management practice, as was observed in attrition of participants. Participant attrition may have contributed to a lack of findings in the adherence analyses. With only two-thirds of participants providing data over the two-week period, power to find significant results was reduced. Although attrition is a common limitation in studies with a follow-up period, it is especially pronounced in studies with a small sample size at initiation. A potential replication study may utilize over-sampling to ensure an adequate number of participants for follow-up analyses. It also may be necessary to spend more time on the instruction and rationale for stress reduction to ensure buy-in of participants with low motivation to engage in regular practice.

Finally, it should be noted that pilot testing did not occur before implementation of the present study. This practice could have illuminated some of the limitations of the study, allowing for improved design prior to data collection.

\section{Directions for Future Research}

The present study provides a fresh look at the specificity hypothesis with the hope that it might lead to optimal selection of efficacious stress management techniques for patients seeking help for stress-related disorders. Although the study reveals that the C-SOSI has promise as a 
valid tool for assessing an individual's stress response, there are several ways in which this research could be furthered. First, in order to assess all domains of the stress response and to profile an individual's unique stress response, each facet must be adequately measured. The present study suggested that more empirical work is needed in examining the cognitive response domain. An individual must be able to clearly report his/her thoughts in response to stressors, and current measures don't appear to provide this opportunity. Given the differential associations among SBP, DBP, and HR with respect to experienced symptoms of stress and predicting efficacy of various types of stress management, it also may be important to profile the physiological response more specifically. For example, an individual's propensity to experience cardiovascular, musculoskeletal, or gastrointestinal distress in response to environmental stressors may be an important distinction to make when choosing stress management interventions and would add another dimension to matching patients with the optimal stress management technique. Thus, it may not be adequate to simply assess one es general physiological stress response in comparison to his/her cognitive or affective stress responses to stress, but rather assess responsivity to stress associated with specific physiological systems. Also important is the degree to which symptoms included on the C-SOSI reflect responses to stress among healthy young adult samples. The C-SOSI was normed using an oncology sample and thus, includes some symptoms that may not be relevant to the stress responses of young adults. The factor structure of the C-SOSI currently is being examined in a healthy, young-adult sample to address this possible limitation.

In addition to further examination of items and factor structure of the C-SOSI, research also could be conducted using other stress management techniques and among patient samples. For example, if an individual experiences significant stress reduction by using a specific 
technique and is able to employ that technique for relief in the presence of acute stressors, he or she may be more likely to practice stress management more frequently. Future intervention studies could be conducted in which individuals confront laboratory stressors on two separate occasions, before and after they have learned and practiced various stress management techniques. Using this approach, one could test the benefits of various stress management techniques (e.g., progressive muscle relaxation, meditation), since they have been shown to have some differential effects among samples of patients with stress-related disorders. The present study could be replicated with other types of stress management to further test the specificity hypothesis.

\section{Clinical Implications}

One of the proposed aims of the present study was to test whether the C-SOSI could aid in the selection of effective stress management techniques. If such an assessment resulted in greater adherence to practicing a given stress management technique, efficacy of that technique presumably would have been enhanced. However, using the C-SOSI for predicting treatment outcomes was not yet supported, at least for interventions involving diaphragmatic breathing relaxation. However, clinicians may be able to use the C-SOSI to thoroughly assess experienced symptoms of stress in multiple domains occurring outside their office. In this regard, the C-SOSI can be a good tool to help clinicians understand a patient ${ }^{\text {ee }}$ general stress response, thus beginning the discussion of how stress impacts the patient ${ }^{\text {ee }}$ life and where they might need to focus their attention. In this regard, although its predictive validity has yet to be established, the C-SOSI holds promise as a comprehensive measurement of the human stress response. 


\section{References}

Ader, R., Cohen, N., \& Felten, D. (1995). Psychoneuroimmunology: Interactions between the nervous system and the immune system. Lancet, 345, 99- 103. doi: 10.1016/S0140$6736 \% 2895 \% 2990066-7$

Allen, M. T., Stoney, C. M., Owens, J. F., \& Matthews, K. A. (1993). Hemodynamic adjustments to laboratory stress: The influence of gender and personality. Psychosomatic Medicine, 55, 505-517.

Almeida, D. M., Wethington, E., \& Kessler, R. C. (2002). The Daily Inventory of Stressful Events: An interview-based approach for measuring daily stressors. Assessment, 9, 41-55. doi: $10.1177 / 1073191102091006$

Avero, P., \& Calvo, M. G. (1999). Emotional reactivity to social-evaluative stress: Gender differences in response systems concordance. Personality and Individual Differences, 27, 155-170. doi:10.1016\%2FS0191-8869\%2898\%2900229-3

Barnes, P. M. Bloom, B., \& Nahin, R. L. (2008). Complementary and alternative medicine use among adults and children: United States, 2007. National Health Statistics Reports, Number 12.

Beck, A. T. (1993). Cognitive approaches to stress. In P. M. Lehrer and R. L. Woolfolk (Eds.), Principles and Practice of Stress Management, Second Edition (pp. 333-372). New York: The Guilford Press.

Benson, H. B. (1975). The Relaxation Response. New York: William Morrow and Company, Inc. 
Berntson, G. G., Bigger Jr., J. T., Eckberg, D. L., Grossman, P., Kaufmann, P. G., Malik, M... Van Der Molen, M. W. (1997). Heart rate variability: Origins, methods, and interpretive caveats. Psychophysiology, 34, 623-648. doi:10.1111\%2Fj.1469-8986.1997.tb02140.x

Brantley, P. J., Cocke, T. B., Jones, G. N., \& Goreczny, A. J. (1988). The Daily Stress Inventory: Validity and effect of repeated administration. Journal of Psychopathology and Behavioral Assessment, 10, 75-81. doi: 10.1007/BF00962987

Cannon, W. B. (1928). The mechanism of emotional disturbance of bodily functions. New England Journal of Medicine, 198, 165-172. doi:10.1056\%2FNEJM192806141981701

Carlson, L. E. \& Thomas, B. C. (2007). Development of the Calgary Symptoms of Stress inventory (C-SOSI). International Journal of Behavioral Medicine, 14, 249-256. doi: 10.1007/BF03003000

Carrico, A. W., Antoni, M. H., Duran, R. E., Ironson, G., Penedo, F., Fletcher, M... Schneiderman, N. (2006). Reductions in depressed mood and denial coping during cognitive behavioral stress management with HIV-positive gay men treated with HAART. Annals of Behavioral Medicine, 31, 155-164. doi: $10.1207 / \mathrm{s} 15324796 \mathrm{abm} 3102 \_7$

Carrington, P. (1993). Modern forms of meditation. In P. M. Lehrer and R. L. Woolfolk (Eds.), Principles and Practice of Stress Management, Second Edition (pp. 139-168). New York: The Guilford Press.

Carver, C. S. (1997). You want to measure coping but your protocol ${ }^{\text {ee }}$ s too long: Consider the Brief COPE. International Journal of Behavioral Medicine, 4, 92-100. doi:10.1207\%2Fs15327558ijbm0401_6 
Carver, C. S., \& Scheier, M. F. (1994). Situational coping and coping dispositions in a stressful transaction. Journal of Personality and Social Psychology, 66, 184-195. doi: $10.1037 / / 0022-3514.66 .1 .184$

Carver, C. S., Scheier, M. F., \& Weintraub, J. K. (1989). Assessing coping strategies: A theoretically based approach. Journal of Personality and Social Psychology, 56, 267-283. doi: $10.1037 / 0022-3514.56 .2 .267$

Chapman, G. B., Brewer, N. T., Coups, E. J., Brownlee, S., Leventhal, H., \& Leventhal, E. A. (2001). Value for the future and preventive health behavior. Journal of Experimental Psychology: Applied, 7, 235-250. doi: 10.1037//1076-898X.7.3.235

Cheng, W. N. K., Hardy, L., \& Markland, D. (2009). Toward a three-dimensional conceptualization of performance anxiety: Rational and initial measurement development. Psychology of Sport and Exercise, 10, 271-278. doi: 10.1016/j.psychsport.2008.08.001

Cohen, J. I. (2000). Stress and mental health: A biobehavioral perspective. Issues in Mental Health Nursing, 21, 185-202. doi: 10.1080/016128400248185

Cohen, S., Kamarck, T., \& Mermelstein, R. (1983). A global measure of perceived stress. Journal of Health and Social Behavior, 24, 385-396. doi: 10.2307/2136404

Cohen, S., \& Rodriguez, M. S. (1995). Pathways linking affective disturbances and physical disorders. Health Psychology, 14, 374-380. doi: 10.1037/0278-6133.14.5.374

Cone, J. D. (1978). The behavioral assessment grid (BAG): A conceptual framework and taxonomy. Behavior Therapy, 9, 882-888. doi:0.1016\%2FS0005-7894\%2878\%29800203 
Davis, M., Eshelman, E. R., \& McKay, M. (2008). The Relaxation and Stress Reduction Workbook, Sixth Edition. Oakland, CA: New Harbinger Publications, Inc.

Eaton, R. J., \& Bradley, G. (2008). The role of gender and negative affectivity in stressor appraisal and coping selection. International Journal of Stress Management, 15, 94-115. doi: $10.1037 \% 2 F 1072-5245.15 .1 .94$

Ellins, E., Halcox, J., Donald, A., Field, B., Brydon, L., Deanfield, J., \& Steptoe, A. (2008). Arterial stiffness and inflammatory response to psychophysiological stress. Brain, Behavior, and Immunity, 22, 941-948. doi: 10.1016/j.bbi.2008.01.009

Erdfelder, E., Faul, F., \& Buchner, A. (1996). GPOWER: A general power analysis program. Behavior Research Methods, Instruments, \& Computers, 28, 1-11.

Fahrenberg, J., Foerster, F., \& Wilmers, F. (1993). Cardiovascular response to mental and physical tasks as predictors of ambulatory measurements. Journal of Psychophysiology, 7, 275-289.

Folkman, S., \& Lazarus, R. S. (1991). Coping and emotion. In A. Monat and R. S. Lazarus (Eds.), Stress and Coping: An Anthology, $3^{\text {rd }}$ ed. (pp. 207-227). NY: Columbia University Press.

Folkman, S., Lazarus, R. S., Dunkel-Schetter, C., DeLongis, A., \& Gruen, R. J. (1986). Dynamics of a stressful encounter: Cognitive appraisal, coping, and encounter outcomes. Journal of Personality and Social Psychology, 50, 992-1003. doi:10.1037\%2F00223514.50.5.992

Folkman, S., \& Moskowitz, J. T. (2004). Coping: Pitfalls and promise. Annual Review Psychology, 55, 745-774. doi: 10.1146/annurev.psych.55.090902.141456 
Forsythe, C. J., \& Compas, B. E. (1987). Interaction of cognitive appraisals of stressful events and coping: Testing the goodness of fit hypothesis. Cognitive Therapy and Research, 11, 473-485. doi:10.1007\%2FBF01175357

Frasure- Smith. N., Lesperance, F., Irwin, M. R., Talajic, M., \& Pollock, B. G. (2009). The relationships among heart rate variability, inflammatory markers, and depression in coronary heart disease patients. Brain, Behavior, and Immunity, 23, 1140-1147. doi: 10.1016/j.bbi.2009.07.005

Fried, R. (1993). The role of respiration in stress and stress control: Toward a theory of stress as a hypoxic phenomenon. In P. M. Lehrer and R. L. Woolfolk (Eds.), Principles and Practice of Stress Management, Second Edition (pp. 301-332). New York: The Guilford Press.

Friedman, H. S., \& Booth-Kewley, S. (1987). The “disease-prone personality": A meta-analytic view of the construct. American Psychologist, 42, 539-555. doi:10.1037\%2F0003066X.42.6.539

Gadzella, B. M. (1994). Student-life stress inventory: Identification of and reactions to stressors. Psychological Reports, 74, 395-402.

Geirdal, A. O. \& Dahl, A. A. (2008). The relationship between coping strategies and anxiety in women from families with familial breast-ovarian cancer in the absence of demonstrated mutations. Psycho-Oncology, 17, 49-57. doi: 10.1002/pon.1198

Goodie, J. L., Larkin, K. T., \& Schauss, S. (2000). Validation of the Polar heart rate monitor for assessing heart rate during physical and mental stress. Journal of Psychophysiology, 14, 159-164. doi:10.1027\%2F\%2F0269-8803.14.3.159 
Goodwin, R. D., \& Friedman, H. S. (2006). Health status and the five-factor personality traits in a nationally representative sample. Journal of Health Psychology, 11, 643-654. doi:10.1177\%2F 1359105306066610

Green, S. B. (1991). How many subjects does it take to do a regression analysis? Multivariate Behavioral Research, 26, 499-510. doi: 10.1207/s15327906mbr2603_7

Haensel, A., Mills, P. J., Nelesen, R. A., Ziegler, M. G., \& Dimsdale, J. E. (2008). The relationship between heart rate variability and inflammatory markers in cardiovascular disease. Psychoneuroendocrinology, 33, 1305-1312. doi:

10.1016/j.psyneuen.2008.08.007

Hamid, A. (2004). Personality correlates of health outcomes in Sudanese university students. Social Behavior and Personality, 32, 321-328.

Heimberg, R. G., Gansler, D., Dodge, C. S., \& Becker, R. E. (1987). Convergent and discriminant validity of the Cognitive- Somatic Anxiety Questionnaire in a social phobic population. Behavioral Assessment, 9, 379-388.

Holmes, T. H. \& Rahe, R. H. (1967). The Social Readjustment Rating Scale. Journal of Psychosomatic Research, 11, 213-218. doi: 10.1016/0022-3999\%2867\%2990010-4

Kern- Buell, C. L., McGrady, A. V., Conran, P. B., \& Nelson, L. A. (2000). Asthma severity, psychophysiological indicators of arousal, and immune function in asthma patients undergoing biofeedback-assisted relaxation. Applied Psychophysiology and Biofeedback, 25, 79-91. doi: 1090-0586/00/0600-0079\$18.00/0

Kershaw, T. S., Wood, D. W., Newth, G., Ronis, D. L., Sanda, M. G., Vaishampayan, U., et al. (2008). Longitudinal analysis of a model to predict quality of life in prostate cancer 
patients and their spouses. Annals of Behavioral Medicine, 36, 117-128. doi: $10.1007 / \mathrm{s} 12160-008-9058-3$

Koh, K. B., Park, J. K., Kim, C. H., \& Cho, S. (2001). Development of the Stress Response Inventory and its application in clinical practice. Psychosomatic Medicine, 63, 668-678.

Krantz, D. S., \& Manuck, S. B. (1984). Acute psychophysiologic reactivity and risk of cardiovascular disease: A review and methodologic critique. Psychological Bulletin, 96, 435-464. doi: 10.1037/0033-2909.96.3.435

Lamiraud, K. \& Geoffard, P. Y. (2007). Therapuetic non-adherence: A rational behavior revealing patient preferences? Health Economics, 16, 1185-1204. doi: $10.1002 \% 2$ Fhec. 1214

Larkin, K. T. (2005). Stress and Hypertension: Examining the Relation between Psychological Stress and High Blood Pressure. New Haven: Yale University Press.

Lawton, R., Conner, M., \& McEachan, R. (2009). Desire or reason: Predicting health behaviors from affective and cognitive attitudes. Health Psychology, 28, 56-65. doi: $10.1037 / \mathrm{a} 0013424$

Lazarus, R. S., \& Folkman, S. (1984). Stress, Appraisal, and Coping. New York: Springer Publishing Co.

Lehrer, P. M., Schoickett, S., Carrington, P., \& Woolfolk, R. L. (1980). Psychophysiological and cognitive responses to stressful stimuli in subjects practicing progressive relaxation and clinically standardized meditation. Behavior Research \& Therapy, 18, 293-303. doi: $10.1016 / 0005-7967 \% 2880 \% 2990088-1$

Lehrer, P. M. \& Woolfolk, R. L. (1993). Principles and Practice of Stress Management, Second Edition (pp. 481-605). New York: The Guilford Press. 
Lovallo, W. R. (1997). Stress \& Health: Biological and Psychological Interactions. Thousand Oaks, CA: Sage Publications.

Lubin, B., Van Whitlock, R., Reddy, D., \& Petren, S. (2001). A comparison of the short and long forms of the Multiple Affect Adjective Checklist- Revised (MAACL-R). Journal of Clinical Psychology, 57, 411-416. doi:10.1002\%2Fjclp.1023

Marler, M. R., Jacob, R. G., Lehoszky, J. P. \& Shapiro, A. P. (1988). The statistical analysis of treatments effects in 24-hour ambulatory blood pressure recordings. Statistics in Medicine, 7, 697-716. doi: 10.1002/sim.4780070608

Matheny, K. B., Aycock, D. W., Curlette, W. L., \& Junker, G. N. (2003). The Coping Resources Inventory for Stress: A measure of perceived resourcefulness. Journal of Clinical Psychology, 59, 1261-1277. doi: 10.1002/jclp.10219

Mattson, M. E., \& Allen, J. P. (1991). Research on matching alcoholic patients to treatments: Findings, issues, and implications. Journal of Addictive Diseases, 11, 33-49.

McEwen. B. S. (1998). Protective and damaging effects of stress mediators. New England Journal of Medicine, 338, 171-179. doi: 10.1056/NEJM199801153380307

Niskanen, J. P., Tarvainen, M. P., Ranta-aho, P. O., \& Karjalainen, P. A. (2002). Software for advanced HRV analysis. University of Kuopio Department of Applied Physics Report, 111.

Park, C. L., Folkman, S., \& Bostrom, A. (2001). Appraisals of controllability and coping in caregivers and HIV+ men: Testing the goodness-of-fit hypothesis. Journal of Consulting and Clinical Psychology, 69, 481-488. doi: 10.1037//0022-006X.69.3.481 
Patel, C. (1993). Yoga-based therapy. In P. M. Lehrer and R. L. Woolfolk (Eds.), Principles and Practice of Stress Management, Second Edition (pp. 89-138). New York: The Guilford Press.

Pawlow, L. A., \& Jones, G. E. (2005). The impact of abbreviated progressive muscle relaxation on salivary cortisol and salivary immunoglobulin A (sIgA). Applied Psychophysiology and Biofeedback, 30, 375-387. doi: 10.1007/s10484-005-8423-2

Pollatos, O., Kirsch, W., \& Schandry, R. (2005). On the relationship between interoceptive awareness, emotional experience, and brain processes. Cognitive Brain Research, 25, 948-962. doi: 10.1016/j.cogbrainres.2005.09.019

Pressman, S. D., \& Cohen, S. A. (2005). Does positive affect influence health? Psychological Bulletin, 131, 925-971. doi: 10.1037/0033-2909.131.6.925

Ptacek, J. T., Pierce, G. R., \& Thompson, E. L. (2006). Finding evidence of dispositional coping. Journal of Research in Personality, 40, 1137-1151. doi: 10.1016/j.jrp.2005.12.001

Rausch, S. M., Gramling, S. E., \& Auerbach, S. M. (2006). Effects of a single session of largegroup meditation and progressive muscle relaxation training on stress reduction, reactivity, and recovery. International Journal of Stress Management, 13, 273-290. doi: $10.1037 / 1072-5245.13 .3 .273$

Sandercock, G. (2007). Normative values, reliability, and sample size estimates in heart rate variability. Clinical Science, 113, 129-130. doi: 0.1042/CS20070137

Schwartz, G. E., Davidson, R. J., \& Goleman, D. J. (1978). Patterning of cognitive and somatic processes in the self-regulation of anxiety: Effects of meditation versus exercise. Psychosomatic Medicine, 40, 321-328. 
Segerstrom, S. C. (2000). Personality and the immune system: Models, mechanisms, and methods. Annals of Behavioral Medicine, 22, 180-190. doi: 10.1007\%2FBF02895112

Selye, H. (1956). The stress of life. New York: McGraw-Hill.

Steinhauser, M., Maier, M., \& Hübner, R. (2007). Cognitive control under stress: How stress affects strategies of task-set reconfiguration. Psychological Science, 18, 540-545. doi: 10.1111/j.1467-9280.2007.01935.x

Tabachnick, B. G. \& Fidell, L. S. (2007). Multiple regression. In Using Multivariate Statistics (5 $5^{\text {th }}$ ed.), pp. 117-194. Boston: Pearson.

Thayer, J. F., \& Fischer, J. E. (2009). Heart rate variability, overnight urinary epinephrine, and C-reactive protein: Evidence for the cholinergic anti-inflammatory pathway in healthy human adults. Journal of Internal Medicine, 265, 439-447. doi: 10.1111/j.13652796.2008.02023.x

Thayer, J. F., Peasley, C., \& Muth, E. R. (1996). Estimation of respiratory frequency from autoregressive spectral analysis of heart period. Biomedical Sciences Instrumentation, 33, 93-99.

Von Kanel, R., Nelesen, R. A., Mills, P. J., Ziegler, M. G., \& Dimsdale, J. E. (2008). Relationship between heart rate variability, interleukin-6, and soluble tissue factor in health subjects. Brain, Behavior, and Immunity, 22, 461-468. doi: 10.1016/j.bbi.2007.09.009

Vyavaharkar, M., Moneyham, L., Tavakoli, A., Phillips, K. D., Murdaugh, C., Jackson, K., \& Meding, G. (2007). Social support, coping, and medication adherence among HIVpositive women with depression living in rural areas of southeastern United States. AIDS Patient Care and STDs, 21, 667-680. doi: 10.1089\%2Fapc.2006.0131 
Weaver, K. E., Llabre, M. M., Duran, R. E., Antoni, M. H., Ironson, G., Penedo, F. J., \& Schneiderman, N. (2005). A stress and coping model of medication adherence and viral load in HIV-positive men and women on highly active antiretroviral therapy (HAART). Health Psychology, 24, 385-392. doi: 10.1037/0278-6133.24.4.385

Wheat, A. L. \& Larkin, K. T. (2010). Biofeedback of heart rate variability and related physiology: A critical review. Applied Psychophysiology Biofeedback, 35, 229-242. doi: $10.1007 / /$ s10484-010-9133-y

Zakowski, S. G., Hall, M. H., Klein, L. C., \& Baum, A. (2001). Appraised control, coping, and stress in a community sample: A test of the goodness-of-fit hypothesis. Annals of Behavioral Medicine, 23, 158-165. doi:10.1207\%2FS15324796ABM2303_3

Zuckerman, M., \& Lubin, B. (1985). Manual for the Multiple Affect Adjective Checklist. San Diego, CA: Educational and Industrial Testing Service. 
Figure 1. Flow of participants in study

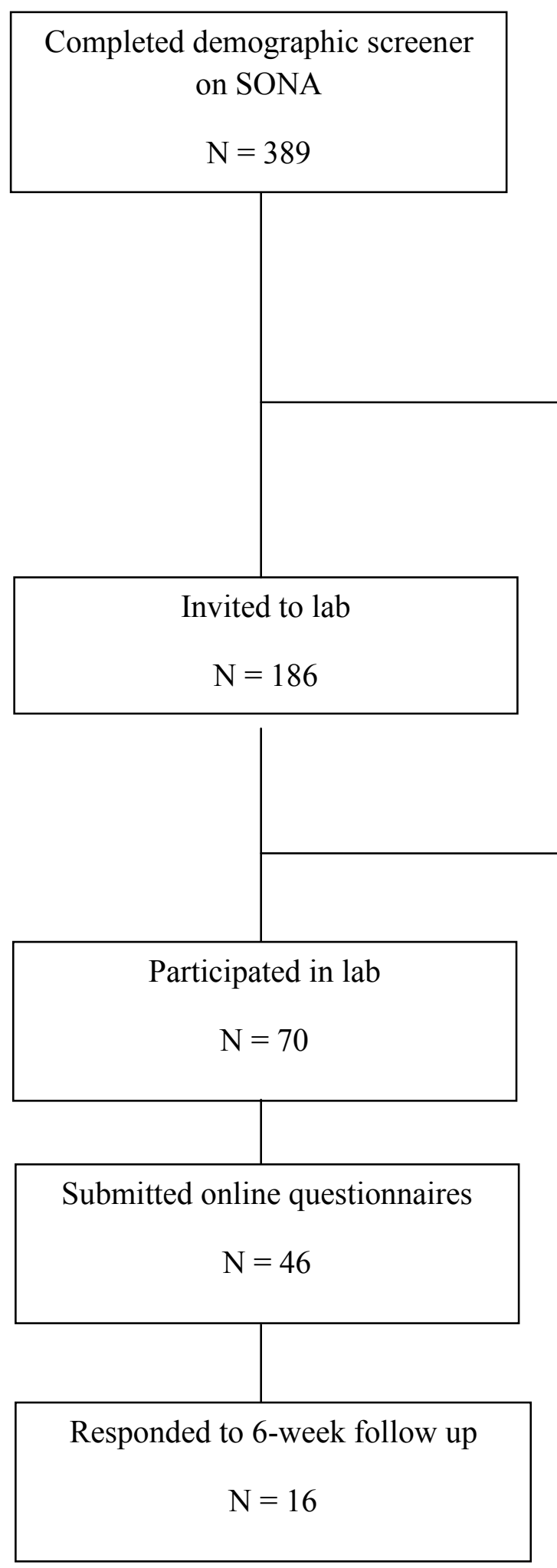

Excluded: *

Cardiovascular Conditions/Medications $(n=47)$

Breathing Conditions (Asthma, Panic) $(\mathrm{n}=58)$

Tobacco Use $(n=38)$

Currently Practicing Relaxation $(\mathrm{n}=73)$

Did not schedule $(\mathrm{n}=110)$

Scheduled but failed to attend $(n=6)$

* Some were excluded for more than one reason 
Table 1. Demographic variables of participants and those who were invited to participate but declined

\begin{tabular}{|c|c|c|c|c|c|}
\hline & $\begin{array}{l}\text { Participants } \\
(\mathrm{n}=70)\end{array}$ & & $\begin{array}{l}\text { Non-participa } \\
(\mathrm{n}=116)\end{array}$ & & $t$ or $\chi^{2}$ \\
\hline & Mean / Freq & $\mathrm{sd} / \%$ & Mean / Freq & $\mathrm{sd} / \%$ & \\
\hline Age (years) & 21.0 & 5.17 & 20.4 & 4.18 & 0.94 \\
\hline Gender & & & & & 0.88 \\
\hline Men & 15 & 21 & 16 & 19 & \\
\hline Women & 55 & 79 & 100 & 81 & \\
\hline Race & & & & & 4.16 \\
\hline White & 53 & 90 & 116 & 94 & \\
\hline Black & 3 & 5 & 1 & 1 & \\
\hline Education & & & & & 0.72 \\
\hline High School & 16 & 27 & 36 & 29 & \\
\hline 1 year college & 15 & 25 & 29 & 23 & \\
\hline 2 years college & 11 & 19 & 27 & 22 & \\
\hline 3 years college & 11 & 19 & 23 & 19 & \\
\hline $4+$ years college & 6 & 10 & 9 & 7 & \\
\hline Medical/Psychiatric & & & & & 0.30 \\
\hline \multicolumn{6}{|l|}{ History } \\
\hline Present & 16 & 27 & 29 & 23 & \\
\hline Absent & 43 & 73 & 95 & 77 & \\
\hline
\end{tabular}


Current Medication Use

Present 31

Absent

28

Alcohol Use (monthly)

Never

1-6 days

7-14 days

14+ days

Caffeine Use (daily)

0-2 cups
3-6 cups
$7+$ cups

Days Moderate Physical

13

27

14

2

3

22

46

24

53

47

66

58

1.21

33

27

57

46

25

20

7

6

53

47

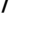

0.01 


\begin{tabular}{|c|c|c|c|c|c|}
\hline $3-6$ & 18 & 31 & 51 & 41 & \\
\hline $7+$ & 0 & 0 & 4 & 3 & \\
\hline Father History of & & & & & 1.79 \\
\hline \multicolumn{6}{|l|}{ Hypertension } \\
\hline Present & 25 & 42 & 43 & 35 & \\
\hline Absent & 25 & 42 & 69 & 55 & \\
\hline Mother History of & & & & & 0.10 \\
\hline \multicolumn{6}{|l|}{ Hypertension } \\
\hline Present & 13 & 22 & 25 & 20 & \\
\hline Absent & 41 & 70 & 89 & 72 & \\
\hline
\end{tabular}

Note. Missing data account for percents totaling less than 100. 
Table 2. Descriptive statistics of C-SOSI subscales for the study sample $(n=70)$

\begin{tabular}{lcc}
\hline Scale & Mean (SD) & Cronbach ${ }^{\text {es } \alpha}$ \\
\hline Anger & $8.0(5.58)$ & 0.89 \\
Depression & $5.9(4.97)$ & 0.78 \\
Cognitive Disorganization & $5.0(3.84)$ & 0.85 \\
Cardiopulmonary Arousal & $2.8(3.61)$ & 0.84 \\
Muscle Tension & $8.2(6.32)$ & 0.80 \\
Neuro/gastrointestinal & $2.3(3.03)$ & 0.81 \\
Sympathetic Arousal & $8.1(6.47)$ & 0.83 \\
Upper Respiratory & $4.8(4.99)$ & 0.94 \\
Total & $45.0(27.07)$ & \\
\hline
\end{tabular}


Table 3. Means (standard deviations) for items on the daily questionnaire $(n=39)$

\begin{tabular}{lc}
\hline Measure & Mean (SD) \\
\hline Days Practiced & $3.0(4.42)$ \\
Daily Stress Level $^{\mathrm{a}}$ & $4.1(1.69)$ \\
Pre-Practice Stress Level $^{\mathrm{a}}$ & $4.4(1.77)$ \\
Post-Practice Stress Level $^{\mathrm{a}}$ & $2.5(1.48)$ \\
Enjoyment Rating $^{\mathrm{b}}$ & $5.1(2.39)$ \\
Benefit Rating $^{\mathrm{c}}$ & $5.5(2.19)$ \\
\hline${ }^{\mathrm{a}}$ non stressed $=0 ;$ stressed very much $=10$ & \\
${ }^{\mathrm{b}}$ did not enjoy $=0 ;$ enjoyed very much $=10$ & \\
${ }^{\mathrm{c}}$ did not help $=0 ;$ helped a lot $=10$ &
\end{tabular}


Table 4. Means (standard deviations) of all study variables for men and women

\begin{tabular}{llll}
\hline & Males $(\mathrm{n}=15)$ & Females $(\mathrm{n}=55)$ & $t$ \\
\hline Active Coping & $15.3(7.41)$ & $16.9(5.51)$ & 0.92 \\
Avoidant Coping & $3.5(2.11)$ & $4.7(2.78)$ & 1.63 \\
Cognitive Anxiety & $24.8(7.17)$ & $32.3(10.55)$ & $2.60^{* *}$ \\
Negative Affect & $0.8(0.81)$ & $1.2(0.83)$ & 1.78 \\
Positive Affect & $0.5(0.37)$ & $0.2(0.25)$ & $-2.55^{*}$ \\
SBP (mm Hg) & $143.6(11.99)$ & $125.5(11.16)$ & $-5.27^{* *}$ \\
DBP (mm Hg) & $81.5(7.78)$ & $77.5(9.33)$ & -1.51 \\
HR (bpm) & $80.1(6.97)$ & $83.9(10.7)$ & 1.64 \\
LF HRV (log) & $1.8(0.06)$ & $1.8(0.06)$ & -0.96 \\
HR HRV (log) & $1.4(0.09)$ & $1.5(0.12)$ & 1.00 \\
C-SOSI Affect & $7.6(5.11)$ & $15.6(9.95)$ & $4.23^{* *}$ \\
C-SOSI Cognitive & $3.5(2.67)$ & $5.4(4.03)$ & 1.67 \\
C-SOSI Physiology & $18.3(9.87)$ & $28.3(18.37)$ & $2.81^{* *}$ \\
Days Practice & $3.7(5.43)$ & $2.8(4.14)$ & -0.69 \\
\hline * $p<.05, * * p<.01$ & & &
\end{tabular}


Table 5. Correlations among study variables

\begin{tabular}{|c|c|c|c|c|c|c|c|c|c|c|}
\hline & $\begin{array}{l}\operatorname{Cog} \\
\text { Anx }\end{array}$ & $\begin{array}{l}\text { Active } \\
\text { COPE }\end{array}$ & $\begin{array}{l}\text { Avoid } \\
\text { COPE }\end{array}$ & $\begin{array}{l}\text { Neg } \\
\text { Affect }\end{array}$ & $\begin{array}{l}\text { Pos } \\
\text { Affect }\end{array}$ & $\begin{array}{l}\text { LF } \\
\text { HRV }\end{array}$ & $\begin{array}{l}\text { HF } \\
\text { HRV }\end{array}$ & SBP & DBP & HR \\
\hline \multicolumn{11}{|l|}{$\operatorname{Cog} A n x$} \\
\hline Active & $.45^{* *}$ & & & & & & & & & \\
\hline \multicolumn{11}{|l|}{ COPE } \\
\hline Avoid & $.54 * *$ & $.46^{* *}$ & & & & & & & & \\
\hline \multicolumn{11}{|l|}{ COPE } \\
\hline Neg & $.62 * *$ & $.36^{* *}$ & $.57 * *$ & & & & & & & \\
\hline \multicolumn{11}{|l|}{ Affect } \\
\hline Pos Affect & $-.35 * *$ & -.10 & -.22 & $-.26 *$ & & & & & & \\
\hline LF HRV & .02 & .12 & .06 & .14 & .10 & & & & & \\
\hline HF HRV & -.01 & -.13 & -.13 & -.14 & .01 & $-.90 * *$ & & & & \\
\hline SBP & .02 & .15 & .18 & .08 & .17 & .15 & -.17 & & & \\
\hline DBP & .04 & .10 & .00 & .01 & .07 & .14 & .00 & $.37 * *$ & & \\
\hline HR & .09 & .10 & -.20 & .12 & -.20 & $.37 * *$ & $-.47 * *$ & .05 & .06 & \\
\hline
\end{tabular}


Table 6. Means (standard deviations) for cognitive, affective, and cardiovascular response to the hand grip and mental arithmetic tasks

\begin{tabular}{|c|c|c|c|c|}
\hline & Grip Task & Arithmetic Task & $t$ & $P$ \\
\hline $\begin{array}{l}\text { Cognitive Response } \\
(\mathrm{n}=70)\end{array}$ & & & & \\
\hline COPE & $16.1(6.93)$ & $17.0(6.56)$ & -1.2 & .24 \\
\hline Active Coping & $6.7(4.83)$ & $4.7(4.87)$ & 3.4 & .001 \\
\hline \multicolumn{5}{|l|}{ Avoidant Coping } \\
\hline Cognitive anxiety & $28.4(9.74)$ & $32.9(12.70)$ & -4.1 & .000 \\
\hline $\begin{array}{l}\text { Affective Response } \\
(\mathrm{n}=70)\end{array}$ & \multicolumn{3}{|c|}{$(\mathrm{n}=70)$} & \\
\hline MAACL-R & $4.9(4.11)$ & $6.0(4.73)$ & -2.2 & .03 \\
\hline Negative Affect & $1.7(2.75)$ & $2.0(3.10)$ & -1.1 & .29 \\
\hline \multicolumn{5}{|l|}{ Positive Affect } \\
\hline \multicolumn{5}{|l|}{ Cardiovascular } \\
\hline \multicolumn{5}{|l|}{ Reactivity } \\
\hline$(\mathrm{n}=70 ; \mathrm{HRV} \mathrm{n}=37)$ & $83.7(12.05)$ & $82.5(11.29)$ & .8 & .41 \\
\hline $\mathrm{HR}(\mathrm{bpm})$ & $133.4(15.43)$ & $125.3(14.56)$ & 5.2 & .000 \\
\hline SBP (mm Hg) & $81.6(12.64)$ & $75.1(9.36)$ & 4.2 & .000 \\
\hline DBP (mm Hg) & $1.8(0.09)$ & $1.8(0.07)$ & -1.5 & .13 \\
\hline Log LF HRV (\%) & $1.5(0.17)$ & $1.4(0.16)$ & 1.3 & .21 \\
\hline Log HF HRV (\%) & & & & \\
\hline
\end{tabular}


Table 7. Regression statistics for predicting coping and cognitive anxiety responses from C-SOSI subscales $(\mathrm{n}=70)$

\begin{tabular}{lllll}
\hline Variables & $B$ & $S E$ B & $\beta$ & $t$
\end{tabular}

Avoidant Coping

Step I: $\mathbf{R}^{2}=.05$

Sex

$-4.44$

2.40

$-.22$

$-1.85$

Step II: $\mathbf{R}^{2}=.21 ; \mathbf{R}^{2} \Delta=.17 *$

Sex

$-1.47$

2.37

$-.07$

$-.62$

C-SOSI Cognitive Disorganization $\quad .27$

.29

.12

.96

C-SOSI Affect

.32

.14

.37

$2.33^{*}$

C-SOSI Physiology (sq rt)

$-.14$

.69

$-.03$

$-.20$

\section{Active Coping}

Step I: $\mathbf{R}^{2}=.01$

Sex

$-.11$

$-.92$

Step II: $R^{2}=.10 ; R^{2} \Delta=.09$

Sex

$-.05$

3.59

$-.02$

$-.15$

C-SOSI Cognitive Disorganization

.35

.43

.10

.71

C-SOSI Affect

.36

.21

.29

1.69

C-SOSI Physiology (sq rt)

$-.29$

1.05

$-.04$

$-.28$ 


\section{Cognitive Anxiety}

Step I: $\mathbf{R}^{2}=.09$

Sex

$-15.07$

5.79

$-.30$

$-2.60$

Step II: $R^{2}=.24 ; R^{2} \Delta=.19^{*}$

Sex

$-8.71$

5.61

$-.17$

$-1.55$

C-SOSI Cognitive Disorganization

.67

.67

.12

.99

C-SOSI Affect

.31

.33

.14

.93

C-SOSI Physiology (sq rt)

3.15

1.64

.27

1.93

$* p=.01$ 
Table 8. Regression statistics for predicting affective responding from C-SOSI subscales $(\mathrm{n}=70)$

Variables $\boldsymbol{B}$

$S E B$

B

$t$

Negative Affect (log)

Step I: $\mathbf{R}^{2}=.12$

Sex

$-.27$

.09

$-.34$

$-2.97 * *$

Step II: $\mathbf{R}^{2}=.28 ; \mathbf{R}^{2} \Delta=.16^{* *}$

Sex

$-.18$

.09

$-. .23$

$-2.03 *$

C-SOSI Cognitive Disorganization

.001

.01

.01

.09

C-SOSI Affect

.005

.005

.15

.94

C-SOSI Physiology (sq rt)

.06

.03

.30

$2.08^{*}$

\section{Positive Affect (log)}

Step I: $\quad R^{2}=.12$

Sex

Step II: $R^{2}=.14 ; R^{2} \Delta=.02$

Sex

C-SOSI Cognitive Disorganization

C-SOSI Affect

C-SOSI Physiology (sq rt)
.33

.02

$-.005$

$-.002$
.12

.01

.01

.04
.34

.16

$-.13$

$-.01$
$2.75 * *$

1.18

$-.75$

$-.06$

${ }^{*} p<.05,{ }^{* *} p<.01$ 
Table 9. Regression statistics for predicting cardiovascular reactivity from C-SOSI subscales $(\mathrm{n}=70)$

Variables

B

$S E B$

$\boldsymbol{\beta}$

Aggregated Cardiovascular

Reactivity

Step I: $\mathbf{R}^{2}=.09$

Sex

.90

.31

$2.66^{*}$

Step II: $R^{2}=.22 ; R^{2} \Delta=.13$

Sex

2.69

.91

.35

$2.97^{*}$

C-SOSI Cognitive Disorganization

$.14 \quad .11$

.16

1.425

C-SOSI Affect

$-.06$

.05

$-.19$

$-1.21$

C-SOSI Physiology (sq rt)

.67

.27

.37

$2.52 *$

SBP (Residualized Change Score)

Step I: $R^{2}=.12$

Sex

1.32

.43

.35

$3.04 *$

Step II: $\mathbf{R}^{2}=.20 ; \mathbf{R}^{2} \Delta=.08$

Sex

1.46

.45

.38

$3.25^{*}$

C-SOSI Cognitive Disorganization

.02

.05

.04

.32

C-SOSI Affect

$-.02$

.02

$-.11$

$-.66$

C-SOSI Physiology (sq rt)

.29

.13

.33

$2.42^{* *}$ 


\section{DBP (Residualized Change Score)}

Step I: $\mathbf{R}^{2}=\mathbf{. 0 2}$

Sex

Step II: $R^{2}=.08 ; R^{2} \Delta=.06$

Sex

C-SOSI Cognitive Disorganization

C-SOSI Affect

$-.004$

.03

$-.03$

$-.16$

C-SOSI Physiology (sq rt)

.14

.26

1.66

\section{HR (Residualized Change Score)}

Step I: $\mathbf{R}^{2}=\mathbf{. 0 2}$

Sex

Step II: $R^{2}=.11 ; R^{2} \Delta=.09$

Sex

C-SOSI Cognitive Disorganization

C-SOSI Affect

C-SOSI Physiology (sq rt)
.51

.45

.14

1.12

.11

.05

.29

2.07

$-.04$

.03

$-.27$

$-1.60$

.14

.13

.17

1.08 


\section{LF HRV ( $\log )$}

Step I: $\mathbf{R}^{\mathbf{2}}=\mathbf{. 0 2}$

Sex

Step II: $R^{2}=.16 ; R^{2} \Delta=.14$

.02

.02

.13

.96

Sex

.03

.02

.23

1.69

C-SOSI Cognitive Disorganization

$-.003$

.003

$-.19$

$-1.32$

C-SOSI Affect

.001

.001

.12

.67

C-SOSI Physiology (sq rt)

.01

.01

.34

$1.97 * *$

\section{HF HRV $(\log )$}

Step I: $\mathbf{R}^{2}=\mathbf{. 0 2}$

Sex

$-.04$

.04

$-.14$

$-1.00$

Step II: $R^{2}=.10 ; R^{2} \Delta=.08$

Sex

C-SOSI Cognitive Disorganization

C-SOSI Affect

C-SOSI Physiology (sq rt)
$-.05$

.003

.000

$-.02$
.04

.005

.002

.01
$-.20$

.09

$-.015$

$-.29$
$-1.34$

.57

$-.08$

$-1.63$

$* \mathrm{p}<.01, * * \mathrm{p}<.05$ 
Table 10. Regression statistics for predicting daily relaxation practice from C-SOSI subscales $(\mathrm{n}=39)$

\begin{tabular}{|c|c|c|c|c|}
\hline Variables & $B$ & $S E B$ & $\boldsymbol{\beta}$ & $t$ \\
\hline \multicolumn{5}{|l|}{ Average Days Practiced (log) } \\
\hline Average Daily Stress Rating & .028 & .040 & .121 & .690 \\
\hline C-SOSI Cognitive Disorganization & -.014 & .020 & -.140 & -.714 \\
\hline C-SOSI Affect & .014 & .015 & .206 & .899 \\
\hline C-SOSI Physiology (sq rt) & -.016 & .010 & -.327 & -1.550 \\
\hline \multicolumn{5}{|l|}{ Average Enjoyment Rating } \\
\hline Average Daily Stress Rating & .323 & .306 & .214 & 1.055 \\
\hline C-SOSI Cognitive Disorganization & .185 & .148 & .287 & 1.252 \\
\hline C-SOSI Affect & -.082 & .104 & -.217 & -.788 \\
\hline C-SOSI Physiology (sq rt) & .007 & .070 & .026 & .105 \\
\hline \multicolumn{5}{|l|}{ Average Benefit Rating } \\
\hline Average Daily Stress Rating & .266 & .282 & .192 & .944 \\
\hline C-SOSI Cognitive Disorganization & .174 & .136 & .294 & 1.276 \\
\hline C-SOSI Affect & -.107 & .096 & -.310 & -1.120 \\
\hline C-SOSI Physiology (sq rt) & .006 & .065 & .024 & .097 \\
\hline \multicolumn{5}{|l|}{ Average Stress Reduction } \\
\hline Average Daily Stress Rating & .046 & .123 & .074 & .375 \\
\hline C-SOSI Cognitive Disorganization & -.074 & .059 & -.280 & -1.258 \\
\hline C-SOSI Affect & .057 & .042 & .363 & 1.362 \\
\hline
\end{tabular}


Table 11. Regression statistics for predicting daily relaxation practice from lab responses $(\mathrm{n}=$ 39)

\begin{tabular}{|c|c|c|c|c|}
\hline Variables & $B$ & $S E B$ & $\boldsymbol{\beta}$ & $t$ \\
\hline \multicolumn{5}{|l|}{ Average Days Practiced (log) } \\
\hline Aggregated Cardiovascular Reactivity & -.01 & .02 & -.05 & -.42 \\
\hline Negative Affect (log) & -.26 & .20 & -.20 & -1.27 \\
\hline Positive Affect (log) & .09 & .14 & .09 & .63 \\
\hline Avoidant Coping & .001 & .008 & .02 & .15 \\
\hline Active Coping & .01 & .005 & .27 & 1.94 \\
\hline \multicolumn{5}{|l|}{ Average Enjoyment Rating } \\
\hline Aggregated Cardiovascular Reactivity & .22 & .10 & .33 & $2.15^{*}$ \\
\hline Negative Affect (log) & .69 & 1.22 & .11 & .57 \\
\hline Positive Affect (log) & .63 & .91 & .11 & .69 \\
\hline Avoidant Coping & -.05 & .05 & -.17 & -.91 \\
\hline Active Coping & .07 & .03 & .34 & 1.89 \\
\hline \multicolumn{5}{|l|}{ Average Stress Reduction } \\
\hline Aggregated Cardiovascular Reactivity & .01 & .05 & .03 & .19 \\
\hline Negative Affect (log) & .51 & .54 & .20 & .94 \\
\hline Positive Affect (log) & .49 & .41 & .22 & 1.21 \\
\hline Avoidant Coping & .04 & .02 & .34 & 1.69 \\
\hline Active Coping & -.03 & .02 & -.39 & -1.97 \\
\hline Average Benefit Rating & & & & \\
\hline
\end{tabular}




\begin{tabular}{lllll}
\hline Aggregated Cardiovascular Reactivity & .14 & .10 & .23 & 1.34 \\
Negative Affect (log) & -.58 & 1.21 & -.10 & -.48 \\
Positive Affect (log) & -.52 & .91 & -.11 & -.58 \\
Avoidant Coping & -.04 & .05 & -.16 & -.80 \\
Active Coping & .06 & .03 & .35 & 1.79 \\
\end{tabular}

$* \mathrm{p}<.05$ 


\section{Appendix A - Demographic Questionnaire}

1. Your age

2. Your sex

o Male

o Female

3. Your race

$\circ$ Black

$\circ$ White

○ Hispanic/Latino

- Native American

$\circ$ Asian

○ Biracial (specify):

$\circ$ Other

4. Total years of education you have completed:

- High school

- 1 year college

- 2 years college

- 3 years college

- 4 or more years college

5. Please describe any cardiovascular related illness that you may have, including high blood pressure:

6. Please list any other medical or psychiatric problems that you have:

7. Please list any major surgeries and medical, or psychiatric illnesses you have had in the past.

8. Please list any drugs (legal or otherwise) that you are currently taking including; birth control (contraceptives), heart medications, cold or allergy medications, over the counter medications, asthma medications, Beta-Blockers (i.e. Inderal, Tenormin), psychoactive drugs (i.e. Adderall, Xanax, Haldol, Lithium, Prozac), or diet pills. 
9. On average, how often do you smoke cigarettes?

$\circ$ never

$\circ$ I am not currently smoking

$\circ$ less than one pack per day

$\circ$ 1-2 packs per day

$\circ$ 2-3 packs per day

$\circ$ greater than 3 packs per day

10. On average, how often do you use smokeless tobacco?

$\circ$ never

$\circ$ I am not currently using smokeless tobacco

$\circ 1-4$ times per day

$\circ$ 5-8 times per day

$\circ 9-13$ times per day

$\circ$ greater than thirteen times per day

11. How often do you drink alcohol?

$\circ$ never

$\circ$ infrequently (a few drinks per year)

$\circ$ occasionally (1-2 drinks per month)

o weekly (2-3 drinks per week)

○ weekly (3-6 drinks per week)

$\circ$ daily (7-14 drinks per week)

$\circ$ daily (more than 14 drinks per week)

12. How many cups of caffeinated coffee, tea, or soda do you have per day?

$\circ$ 1-2 cups per day

$\circ$ 3-4 cups per day

$\circ 5-6$ cups per day

$\circ$ 7-8 cups per day

$\circ$ greater than eight cups per day

We are interested in two types of physical activity- moderate and vigorous. Moderate activities cause small increases in breathing or heart rate, and vigorous activities cause large increases in breathing or heart rate.

13. How many times per week do you engage in moderate physical activity (e.g. brisk walking, bicycling, gardening, or other activity that causes increase in breathing or heart rate) for at least 10 minutes at a time?

$\circ$ never

$\circ 1-2$ times

○ 3-6 times

$\circ 7$ or more times 
14. On days that you do moderate activities for at least 10 minutes at a time, how much total time per day do you spend doing these activities?

○ $10-30$

o 30-60 minutes

$\circ$ more than 60 minutes

15. How many times per week do you engage in vigorous physical activity (e.g, aerobics, heavy yard work, or other activity that causes large increases in breathing or heart rate.) for at least 10 minutes at a time?
o never
○ 1-2 times
○ 3-6 times
○ 7 or more times

16. On days that you do vigorous activities for at least 10 minutes at a time, how much total time per day do you spend doing these activities?

० $10-30$

○ 30-60 minutes

o more than 60 minutes

17. Approximately how old is your father?

18. Is he currently living?
o yes
o no

19. Did/does your father have high blood pressure (hypertension)?

$$
\begin{aligned}
& \circ \text { yes } \\
& \circ \text { no }
\end{aligned}
$$

20. How certain are you that he did, or did not, have high blood pressure (hypertension)?

$\circ$ Absolutely (100\%) certain

○ Almost (75\%) certain

$\circ$ Not sure at all (25\%)

$\circ$ No information by which to judge $(0 \%)$

21. Did/does your father have any heart problems such as angina (chest pains), a heart attack, or coronary heart disease?

$\circ$ yes
$\circ$ no

22. If yes, please specify if you are able: 
23. How certain are you that he did, or did not, have a heart problem as indicated above?

o Absolutely (100\%) certain

$\circ$ Almost $(75 \%)$ certain

$\circ$ Not sure at all $(25 \%)$

$\circ$ No information by which to judge $(0 \%)$

24. Approximately how old is your mother?

25. Is she currently living?

o yes

$\circ$ no

26. Did/does your mother have high blood pressure (hypertension)?

o yes

$\circ$ no

27. How certain are you that she did, or did not, have high blood pressure (hypertension)?

$\circ$ Absolutely $(100 \%)$ certain

$\circ$ Almost $(75 \%)$ certain

$\circ$ Not sure at all $(25 \%)$

$\circ$ No information by which to judge $(0 \%)$

28. Did/does your mother have any heart problems such as angina (chest pains), a heart attack, or coronary heart disease?

$\circ$ yes

o no

29. If yes, please specify if you are able:

30. How certain are you that she did, or did not, have a heart problem as indicated above?

$\circ$ Absolutely (100\%) certain

- Almost (75\%) certain

○ Not sure at all (25\%)

$\circ$ No information by which to judge $(0 \%)$ 


\section{Appendix B- Daily Questionnaire}

Please answer the following questions about your experience with stress and stress management today. Remember to answer the questions as honestly as possible. We are interested in your actual experience with and perceptions about stress management, so there are no right or wrong answers.

1. On a scale of $0-10$ (with $0=$ not stressful and $10=$ very stressful), how would you rate your overall stress level today?

2. Did you practice the stress reduction technique today? (If No, skip to question 7) $\mathrm{Y}$ N

3. On a scale of $0-10$ (with $0=$ not stressed and $10=$ very stressed), how would you rate your stress level just before you used the breathing CD?

4. On a scale of $0-10$ (with $0=$ not stressed and $10=$ very stressed), how would you rate your stress level after you used the breathing CD?

5. On a scale of $0-10$ (with $0=$ did not enjoy and $10=$ enjoyed very much), how would you rate your enjoyment of the stress reduction technique today?

6. On a scale of $0-10$ (with $0=$ did not help and $10=$ helped a lot), how would you rate the usefulness of the stress reduction technique today?

7. If you did not practice today, what were some barriers or reasons that you did not? 


\section{Appendix C - Diaphragmatic Breathing Script}

In this part of the study, you will be instructed in a relaxation breathing technique that you will be asked to practice for the next two weeks. To start, begin to focus your attention on your breath. Place your feet flat on the floor and lean back in the chair in a comfortable sitting position. Do not try to breathe differently, just notice your breath. (Pause.) Place one hand on your stomach and one hand on your chest. Watch your hands move as you continue to focus on breathing in and out, without changing your breath. See if you notice one hand moving more than the other. (Pause.) What did you notice as your paid attention to your breath? (Elicit feedback from participant.) Many people notice that the hand on their chest moves more than the hand on their stomach. This is how we breathe on a daily basis, without paying much attention to it. Shallow, chest breathing is also part of the fight-or-flight response that we experience when we are stressed. It allows oxygen to be exchanged quickly, but it can result in hyperventilationlike breathing, which can make us feel more anxious or stressed. We can learn to breathe differently, using different muscles that draw more air in. When you learn to do this deep breathing, you will notice your abdomen moving more than your chest. Deeper breathing can provide immediate relief when stressed by slowing down the fight-or-flight response and has benefits for mental and physical health when practiced long-term. I will demonstrate deep breathing first and then ask you to practice with me. It can be helpful to start by forcefully exhaling, pushing all the air out of your lungs. You will notice your stomach muscles tightening and your abdomen moving back toward your spine. This will create more space in your lungs so that when you inhale next, you will naturally take in more air without having to try to take a deep breath. You will see you stomach move forward. Watch how this looks. (Demonstrate.) Now let"s try it together. Exhale forcefully, pushing out all the air. When you inhale, do not try to take 
a deep breath, just let it come naturally. (Practice several times with participant, providing feedback.) As you continue to breathe deeper, you will not need to forcefully exhale anymore. Take a few more deep breaths at your own pace and watch your stomach rise and fall. (Pause.) When you ere first learning how to do this breathing, it may feel unnatural and require more effort and attention. With practice, though, it quickly will become more natural and relaxing. It may be helpful to imagine a balloon in your stomach. Imagine as you inhale, that you are filling the balloon with air, and it expands in your abdomen. As you exhale, the balloon deflates, and all the air rushes out. (As participant practices, provide corrective feedback as necessary.) Sometimes people report that they feel a little light-headed as they are practicing. If you notice this, simply take a break from the deep breathing, and then go back to it when you are ready. I'm going to let you practice this on your own for a few minutes. Do you have any questions about the technique you just learned? (Answer questions as needed.) For the next few minutes, simply relax and breathe. You may close your eyes if that is comfortable for you. The important thing is just to continue breathing deeply at your own pace, paying attention to the rise and fall of your stomach as you breathe in and out, feeling the relaxation that comes with deep breathing. At the end of the practice, I will take your blood pressure one more time. You can rest your arm on the chair so that your blood pressure can be measured. (Leave room and let participant practice for five minutes.) 


\section{Curriculum Vita}

\section{Lauren M. Penwell, M.A.}

\section{EDUCATION}

\section{8/07- Present West Virginia University, Morgantown, WV}

- Clinical Psychology, APA-Approved Health Area of Emphasis

- Advanced to Doctoral Candidacy August 2008

○ M.A. Psychology received December 2008

- Ph.D. anticipated August 2012

- Dissertation: "Validation of the Calgary Symptoms of Stress Inventory (CSOSI) for Predicting Adherence to a Stress Reduction Technique"

○ Advisor: Kevin Larkin, Ph.D.

- Defended November 2011

\section{8/06-7/07 Appalachian State University, Boone, NC}

- Clinical Health Psychology

- Thesis: "Incidence of Upper Respiratory Tract Infections among Competitive Cyclists as a Function of Neuroticism, Quercetin Supplementation, and Intense Exercise"

○ Advisor: Courtney Rocheleau, Ph.D.

○ Defended July 2007

\section{8/02-5/06 West Virginia University, Morgantown, WV}

- B.A. Psychology

- Graduated summa cum laude

- Honors thesis: "Hostility and Cardiovascular Responses to Interpersonal Conflict and Interpersonal Support Tasks among Young Men and Women"

- Advisor: Kevin Larkin, Ph.D. 


\section{CLINICAL EXPERIENCE}

- Psychology Resident, Georgia Health Sciences University (GHSU)/ Charlie Norwood VAMC, Augusta, GA (July 2011- Present)

- APA- Approved Health Behavior Track

○ Track rotation clinics and supervisors (7/1/11- 10/31/11):

- VAMC Women 's Primary Care Clinic/Women's Health Psychology (Rebecca Jump, Ph.D.): psychological consultation and screening, brief outpatient psychotherapy

- VAMC Patient Aligned Care Teams (Ralph Bruno, Ph.D.): psychoeducation and motivational interviewing in diabetes and hypertension shared medical appointments

- VAMC Medical Rehabilitation Unit (Jennifer Whitford, Ph.D.): cognitive evaluations, psychological intake evaluations, individual psychotherapy, interdisciplinary team conferences, neurocognitive testing

- GHSU Cancer Center (Lara Stepleman, Ph.D.): multidisciplinary breast cancer clinic conferences, psychological screening

- GHSU Weight Loss Clinic (Christian Lemmon, Ph.D.): pre-bariatric surgery evaluations, multidisciplinary team conferences

- VAMC Trauma Recovery Clinic (Lorraine Braswell, Ph.D.): Cognitive Processing Therapy group, individual outpatient psychotherapy

- VAMC Polytrauma Outpatient Clinic (Jennifer Whitford, Ph.D.): multidisciplinary TBI evaluations, individual outpatient psychotherapy, neurocognitive testing, interdisciplinary team conferences

- VAMC Blind Rehabilitation Unit (Nick Nichols, Ph.D.): developing and implementing positive psychology group

- Medical psychology rotation clinics and supervisors (11/1/11- Present):

- VAMC OEF/OIF Primary Care Mental Health Integration Clinic (Dustin Wright, Ph.D.): psychological evaluation, brief outpatient psychotherapy

- Augusta Multiple Sclerosis Center (Lara Stepleman, Ph.D.): psychological consultation cognitive evaluation with multidisciplinary team

- GHSU Infectious Disease Clinic (Lara Stepleman, Ph.D.): psychological consultation in HIV/AIDS clinic with multidisciplinary team

- VAMC Spinal Cord Injury Unit (Rebecca Moberly, Ph.D.): annual evaluations and brief interventions with multidisciplinary team

- GHSU Pediatric Endocrinology Clinic (Alex Mabe, Ph. D.): consultation and brief intervention with pediatric diabetes patients and families

- Psychology Extern, Mary Babb Randolph Cancer Center and Bone Marrow Transplant Unit, WVU Ruby Memorial Hospital (June 2010- 2011)

○ Supervisor: Kevin Larkin, Ph.D.

- Brief assessments of mental status and psychosocial functioning, stress management, providing support, facilitating adjustment to illness, consultation as part of multidisciplinary team

- Graduate Student Consultant, Wellness Council of West Virginia (January- May 2010)

○ Supervisor: Kevin Larkin, Ph.D. 
- Consultation and program development for contracted wellness sites, stress management presentations

- Graduate Student Consultant, WVU Department of Exercise Physiology Human Performance Lab (August- December 2009)

- Supervisor: Kevin Larkin, Ph.D.

- Stress management and social support for cardiac rehabilitation patients and diabetes study patients as part of a multidisciplinary team

- Student Supervisor/ Trainee, Quin Curtis Center Vertical Team (August 2009- 2010)

○ Supervisor: Kevin Larkin, Ph.D.

- Forgiveness protocol intervention, individual treatment for community referrals, supervision of graduate student therapist

- Practicum Student, Wedgewood Psychiatry Associates (July 2008- 2009)

○ Supervisor: Martin Boone, Ph.D.

- Neuropsychological assessment

- $\quad$ Student Trainee, Quin Curtis Center Vertical Team (August 2008- 2009)

o Supervisor: Daniel W. McNeil. Ph.D.

- Individual cognitive behavioral treatment for anxiety disorders

- Student Trainee, Geropsychology and Insomnia Team, WVU Hospitals Department of Family Medicine, Morgantown, WV (August 2007- 2008)

○ Supervisor: Amy Fiske, Ph.D.

- Individual and group cognitive behavioral treatment for insomnia and mood disorders

- $\quad$ Student Trainee, ASU Psychology Clinic, Boone, NC (January - April 2007)

○ Supervisor: Hank Schneider, Ph.D.

- ADHD and learning disability assessments

- Undergraduate Trainee, Chestnut Ridge Hospital, WVU Department of Behavioral Medicine and Psychiatry, Morgantown, WV (May - August 2005)

○ Supervisors: Marc Haut, Ph.D., ABPP

- Neuropsychological assessment

\section{PUBLICATIONS}

Penwell, L. M., Larkin, K. T., \& Goodie, J. L. (In press). Biopsychosocial assessment of coping. In F. Andrasik, J. L. Goodie, \& A. Peterson (Eds.), Biopsychosocial assessment in clinical health psychology: A handbook. New York: Guilford Press.

Penwell, L. M., \& Larkin, K. T. (2010). Social support and risk for cardiovascular disease and cancer: A qualitative review examining the role of inflammatory processes. Health Psychology Reviews, 4, 42-55.

Matthews, M. R. H., Harris, C. V., Bradlyn, A. S., Moore, L. C., Blake, K. B., \& Penwell, L. M. (Under review). Parental reports of weight-based teasing and weight-control practices among their children. Body Image. 


\section{PROFESSIONAL PRESENTATIONS}

Penwell, L. M., Moore, L. C., Harris, C. V., Bradlyn, A. S., Blower, K., Purkey, M., Kennedy, K., et al. (2011, April). Family nutrition and physical activity environments predict child health behaviors. Presented at the $32^{\text {nd }}$ Annual Meeting of the Society of Behavioral Medicine, Washington, DC.

Penwell, L. M., Kemmner, C., Whited, M., Larkin, K. T., \& Ale, C. M. (2010, April). Behavioral responses to interpersonal tasks among high-and low-hostile men and women. Presented at the $31^{\text {st }}$ Annual Meeting of the Society of Behavioral Medicine, Seattle, WA.

Kemmner, C., Penwell, L. M., Whited, M., Larkin, K. T., \& Ale, C. M. (2010, April). Cardiovascular reactivity and behavioral responding to an interpersonal stressor task. Presented at the $31^{\text {st }}$ Annual Meeting of the Society of Behavioral Medicine, Seattle, WA.

Prentice, P. R., Whited, M., Penwell, L. M., Larkin, K. T., Ale, C. M., Kemmner, C., Sundin, K., $\&$ Wheat, A. L. (2009, March). Gender role moderates heart rate variability response and eye contact during interpersonal stress. Presented at the $67^{\text {th }}$ Annual Meeting of the American Psychosomatic Society, Chicago, IL.

Kemmner, C., Ale, C. M., Whited, M., Penwell, L.M., Sundin, K., \& Larkin, K. T. (2009, March). Heart rate, heart rate variability, and interpersonal motives related to eye-gaze avoidance in an interpersonal task. Presented at the $67^{\text {th }}$ Annual Meeting of the American Psychosomatic Society, Chicago, IL.

Penwell, L. M. (2008). Stress and sleep. In Touch and Concerned Fall newsletter.

Penwell, L.M., Rocheleau, C.A., Huelsman, T.J., \& Broman-Fulks, J.J. (2008, May). Antioxidant supplement buffers effects of neuroticism on illness. Presented at the $20^{\text {th }}$ annual Association for Psychological Science convention, Chicago, IL.

Penwell, L.M., Whited, M.C., \& Larkin, K.T. (2008, March). Cardiovascular, affective, and interpersonal motive responses to conflict and comfort tasks among high and low hostile men and women. Presented at the $66^{\text {th }}$ Annual Meeting of the American Psychosomatic Society, Baltimore, MD.

Rocheleau, C.A., Huelsman, T.J., Penwell, L.M., \& Nieman, D.C. (2007, August and June). The benefits of quercetin on cognitive functioning after intense exercise. Presented at the $115^{\text {th }}$ APA Annual Conference, San Francisco, CA, and at the ACSM Annual Convention, New Orleans, LA.

MacLaren, J.E., Cohen, L.L., Penwell, L.M., Hitchens, L., Speer, K.L., Chorney, D.B., \& Stanley, V. (2006, April). Improving pain management in children: Training nursing 
students in evidence-based behavioral techniques. Presented at the $10^{\text {th }}$ National Conference on Child Health Psychology, Gainesville.

\section{RESEARCH ACTIVITY}

- Manuscripts in progress

- Differential coping responses among hematologic malignancy patients receiving hematopoietic stem cell transplantation vs. those receiving chemotherapy

$\circ$ Does body size satisfaction influence weight-related health beliefs and intention to lose weight?

- School-based obesity prevention: the role of the school nurse

- Current data collection/ analysis

- Georgia Health Sciences University Department of Family Medicine (August 2011Present)

- Psychosocial influences in advance directives

- Co-Investigators: Lauren Penwell and Ralph Gillies, Ph.D.

○ West Virginia University Department of Psychology (April 2011- Present)

- Validation of a Stress Inventory in College Students

- Co-Investigators: Lauren Penwell and Kevin Larkin, Ph.D.

- WVU Hospitals Bone Marrow Transplant Unit (June 2010- Present)

- Effect of Bone Marrow Transplant Preparatory Regimens on Cognitive Functioning and Psychological Well-being among Blood and Marrow Transplant Patients

- PI: Kevin Larkin, Ph.D.

- Previous research experience

○ WVU School of Medicine Health Research Center (May 2010- 2011)

- Program evaluation of WVU Office of Health Services Research, Communities Putting Prevention to Work, WV Healthy Lifestyles Act

- PI: Carole Harris, Ph.D., and Drew Bradlyn, Ph.D.

○ WVU School of Medicine Center for Neuroscience (March 2009- January 2010)

- Changing Perception of Others through Compassion Meditation

- PI: Julie Lewis, Ph.D., and Jim Lewis, Ph.D.

○ WVU Dept of Psychology and Dept of Family Medicine (July 2008 - February 2011)

- Insomnia and Emotion Regulation

- PI: Amy Fiske, Ph.D.

○ WVU Dept of Psychology (August 2008-2010)

- Grudge Forgiveness Project

- PI: Kevin Larkin, Ph.D.

○ WVU Student Wellness Advisory Board (February 2008- July 2009)

- Student wellness needs assessment

- PI: Keith Zullig, Ph.D., Colleen Harshbarger, M. S.

○ Appalachian State University Dept of Psychology (August 2006- May 2007)

- Animal models of contextual cues in fear and anxiety conditioning 
- PI: Jim Denniston, Ph.D.

\section{TEACHING EXPERIENCE}

- Psychiatry Grand Rounds presentation, Georgia Health Sciences University Dept of Psychiatry and Health Behavior (November 10, 2011)

- Title: Predicting and Enhancing Adherence to Stress Management

- Supervision of undergraduate research and teaching assistants, WVU Dept of Psychology (2007- 2011)

- Member, Undergraduate Honors Thesis Committee, WVU Dept of Psychology (20092010)

- Topic: Examination of Varying Cardiovascular, Behavioral, Affective and Motives-Based Responses to Interpersonal Stressor Tasks

- Guest Lecturer, Lifespan Developmental Psychopathology, WVU Dept of Psychology (November 19, 2009)

- Graduate Instructor, Abnormal Psychology, WVU Dept of Psychology (Fall 2009- Spring 2010)

○ Supervisor: Amy Fiske, Ph.D.

- 1 section of 117 students each semester

- Graduate Instructor, Introduction to Psychology, WVU Dept of Psychology (Fall 2007Spring 2008)

○ Supervisors: Hawley Montgomery-Downs, Ph.D., Claire St. Peter-Pipkin, Ph.D.

○ 1 section of 117 students each semester

\section{HONORS AND AWARDS}

- Psi Chi Psychology Honorary

- Phi Beta Kappa

- WVU Department of Psychology Travel Grant (2008, 2010, 2011)

- WVU Eberly College Graduate Student Travel Grant (2008, 2010, 2011)

- WVU Office of Academic Affairs Doctoral Student Travel Program $(2008,2010,2011)$

- WVU Department of Psychology Alumni Fund Dissertation Award (2009-2010)

- Biomedical and Behavioral Sciences Training Scholarship (2010)

\section{EDITORIAL ACTIVITY}


- Reviewed manuscripts for Psychosomatic Medicine, Annals of Behavioral Medicine, and Journal of Behavioral Medicine (2008-2011)

- Reviewed grant applications and research awards for Association for Psychological Science (2008-2009)

- Reviewed abstracts for American Psychosomatic Society annual conference (November 2008)

\section{ASSOCIATION AND COMMITTEE MEMBERSHIPS}

- Society of Behavioral Medicine (2009- Present)

- American Psychological Association (2006- Present)

- APA Division 38- Health Psychology

- WVU Department of Psychology Wellness Committee (2008-2009)

- WVU Student Wellness Advisory Board (Member, 2009-2011; Vice President, 20092010)

- $\quad$ APA Graduate Student (APAGS) Campus Representative, WVU Department of Psychology (June 2010- May 2011)

- Graduate Student Representative, Holistic Graduate Training Working Group, Eberly College of Arts and Sciences Research and Graduate Education Committee for WVU 2020 Strategic Plan (2011) 